\title{
Imbalance of Lysine Acetylation Contributes to the Pathogenesis of Parkinson's Disease
}

\author{
Rui Wang ${ }^{\dagger}$, Hongyang Sun ${ }^{\dagger}$, Guanghui Wang * and Haigang Ren * \\ Laboratory of Molecular Neuropathology, Jiangsu Key Laboratory of Neuropsychiatric Diseases \& Department \\ of Pharmacology, College of Pharmaceutical Sciences, Soochow University, Suzhou 215123, China; \\ rwang0828@stu.suda.edu.cn (R.W.); 20184026011@stu.suda.edu.cn (H.S.) \\ * Correspondence: wanggh@suda.edu.cn (G.W.); rhg@suda.edu.cn (H.R.); Tel.: +86-512-65884845 (G.W.); \\ +86-512-65882527 (H.R.) \\ † These authors contribute equally to this work.
}

Received: 27 August 2020; Accepted: 24 September 2020; Published: 29 September 2020

\begin{abstract}
Parkinson's disease (PD) is one of the most common neurodegenerative disorders. The neuropathological features of PD are selective and progressive loss of dopaminergic neurons in the substantia nigra pars compacta, deficiencies in striatal dopamine levels, and the presence of intracellular Lewy bodies. Interactions among aging and genetic and environmental factors are considered to underlie the common etiology of PD, which involves multiple changes in cellular processes. Recent studies suggest that changes in lysine acetylation and deacetylation of many proteins, including histones and nonhistone proteins, might be tightly associated with PD pathogenesis. Here, we summarize the changes in lysine acetylation of both histones and nonhistone proteins, as well as the related lysine acetyltransferases (KATs) and lysine deacetylases (KDACs), in PD patients and various PD models. We discuss the potential roles and underlying mechanisms of these changes in PD and highlight that restoring the balance of lysine acetylation/deacetylation of histones and nonhistone proteins is critical for PD treatment. Finally, we discuss the advantages and disadvantages of different KAT/KDAC inhibitors or activators in the treatment of PD models and emphasize that SIRT1 and SIRT3 activators and SIRT2 inhibitors are the most promising effective therapeutics for PD.
\end{abstract}

Keywords: Parkinson's disease; lysine acetylation; lysine acetyltransferases; lysine deacetylases; histone; nonhistone; mitochondria

\section{Introduction}

Parkinson's disease (PD) is the second most common neurodegenerative disorder, affecting approximately $1 \%$ of the population over the age of 60 and, drastically, up to $5 \%$ of the population over 85 [1,2]. PD primarily causes motor symptoms such as bradykinesia, rigidity, resting tremor, and gait impairment, as well as some nonmotor symptoms, including olfactory disorders, sleep disturbances, anosmia, constipation, cognitive decline, and depression [3]. Selective and progressive loss of dopaminergic (DA) neurons in the substantia nigra pars compacta (SNpc) that leads to deficiencies in striatal dopamine production, as well as intracellular inclusions containing $\alpha$-synuclein ( $\alpha$-syn) aggregates referred to as Lewy bodies (LBs) in surviving neurons, are the neuropathological features of PD [4,5]. Levodopa (L-DOPA) therapy to supplement dopamine is currently the most effective treatment for PD [6]. However, neither L-DOPA nor any other currently available therapies can slow down or prevent progressive DA neuronal degeneration in PD brains.

Although the pathogenesis of PD is still elusive, the interactions among aging and genetic and environmental factors are considered to underlie the common etiology of PD [7]. Aging is recognized 
as a critical risk factor for PD, and as the population ages, the incidence and prevalence of PD will likely increase by more than $30 \%$ by 2030 [8,9]. Although PD in most patients is idiopathic, approximately $5-10 \%$ of patients suffer from familial PD with Mendelian inheritance, and to date, more than 20 genes that cause familial PD have been identified; these genes are referred to as "PARK" genes, including PARK1 (encoding $\alpha$-syn), PARK2 (encoding Parkin), PARK6 (encoding PTEN-induced putative kinase 1, PINK1), PARK8 (encoding leucine-rich repeat kinase 2, LRKK2), PARK9 (encoding ATPase 13A2, ATP13A2), etc. $[10,11]$. Their main functions are shown in Table 1. In addition, genome-wide association studies (GWASs) have identified common genetic variants that increase PD risk [7,12]. In addition to aging and genetic factors, environmental factors are also closely related to PD occurrence and development. Environmental factors including the neurotoxin phenyl-1,2,3,6-tetrahydropyridine (MPTP) and its metabolite 1-methyl-4-phenylpyridinium iodide $\left(\mathrm{MPP}^{+}\right)$; 6-hydroxydopamine (6-OHDA); paraquat; and several pesticides, such as rotenone and dieldrin, can induce PD or increase the risk of PD [7].

Table 1. PD-Causing Genes and their Main Functions.

\begin{tabular}{|c|c|c|}
\hline Gene & Encoding Protein & Main Functions \\
\hline PARK1/SNCA & $\alpha$-syn & Synaptic function \\
\hline PARK2/PRKN & Parkin & Ubiquitination; synaptic function \\
\hline PARK3/PARK3 & Parkinson disease 3 & Unknown \\
\hline PARK5/UCHL1 & Ubiquitin C-terminal hydrolase L1 & Ubiquitin-proteasome system; autophagy \\
\hline PARK6/PINK1 & PINK1 & Mitochondrial function; mitophagy \\
\hline PARK7/DJ-1 & DJ-1 & Mitochondrial function; anti-oxidative stress; \\
\hline PARK8/LRKK2 & LRKK2 & $\begin{array}{c}\text { Vesicle transport; autophagy; synaptic } \\
\text { function }\end{array}$ \\
\hline PARK9/ATP13A2 & ATP13A2 & Lysosomal function; mitochondrial function \\
\hline PARK10/PARK10 & Parkinson disease 10 & Unknown \\
\hline PARK11/GIGYF2 & GRB10 interacting GYF protein 2 & Growth factors (IGFs) signaling \\
\hline PARK12/PARK12 & Parkinson disease 12 & Unknown \\
\hline PARK13/HTRA2 & HtrA serine peptidase 2 & Mitochondrial function; anti-oxidative stress \\
\hline PARK14/PLA2G6 & Phospholipase A2 group VI & Lipid metabolism; mitochondrial function \\
\hline PARK15/FBXO7 & F-box protein 7 & Mitochondrial function; ubiquitination \\
\hline PARK16/PARK16 & Parkinson disease 16 & Unknown \\
\hline PARK17/VPS35 & VPS35 endosomal protein sorting factor & Vesicle transport \\
\hline PARK18/EIF4G1 & Eukaryotic translation initiation factor & Translation initiation \\
\hline PARK19/DNAJC6 & $\begin{array}{l}\text { DnaJ heat shock protein family (Hsp40) } \\
\text { member C6 }\end{array}$ & Endocytosis; synaptic function \\
\hline PARK20/SYNJ1 & Synaptojanin 1 & Endocytosis; synaptic function \\
\hline PARK21/TMEM230 & Transmembrane protein 230 & Vesicle trafficking; synaptic function \\
\hline PARK22/CHCHD2 & $\begin{array}{l}\text { Coiled-coil-helix-coiled-coil-helix } \\
\text { domain containing } 2\end{array}$ & Mitochondrial function \\
\hline PARK23/VPS13C & Vacuolar protein sorting 13 homolog $C$ & Mitochondrial function; mitophagy \\
\hline
\end{tabular}

The molecular pathogenesis of PD is extremely complicated and involves changes in and dysregulation of various basic physiological processes, such as transcriptional changes, mitochondrial damage, metabolic dysfunction, protein clearance system impairment, oxidative stress, and neuroinflammation $[13,14]$. Research on genetic and environmental factors related to the neurodegeneration of DA neurons and $\alpha$-syn aggregates has provided extensive evidence motivating us to deeply investigate PD pathogenesis. Recent investigations have suggested that lysine acetylation and deacetylation of numerous proteins, including histones and nonhistone proteins, as well as acetylation of $\alpha$-syn itself, might be tightly associated with the molecular events underlying PD pathogenesis. In this review, we discuss the potential roles and mechanisms of lysine acetylation and deacetylation of histones and nonhistone proteins as well as the changes in lysine acetyltransferases (KATs) and lysine deacetylases (KDACs) associated with PD pathogenesis. In addition, we discuss promising KAT/KDAC inhibitors or activators for PD treatment. 


\section{Lysine Acetylation and Its Regulatory Mechanism and Functions}

\subsection{Lysine Acetylation and Its Functions}

Lysine acetylation in histones was first described by Vincent Allfrey and his colleagues in 1964 [15]. Lysine acetylation is an evolutionarily conserved and reversible posttranslational modification (PTM) in eukaryotes that precisely governs protein functions and involves transfer of an acetyl group donated by acetyl coenzyme A (Ac-CoA) to the $\varepsilon$-amino side chain of a protein lysine residue. Lysine acetylation occurs in both histones and nonhistone proteins. Lysine acetylation of histones such as Histone 2A (H2A), Histone 2B (H2B), Histone $3(\mathrm{H} 3)$, and Histone 4 (H4) generally results in transcriptional activation due to destabilization of DNA-histone binding, as acetylation of lysine neutralizes its positive charge, which prevents the formation of salt bridges with the negatively charged phosphate backbone of DNA [16]. In addition to histones, many nonhistone proteins in the cytoplasm and organelles are also dynamically acetylated and deacetylated; these changes are closely implicated in the regulation of various cellular processes, including gene transcription; cell cycle progression; DNA damage repair; cellular signal transduction; protein folding stability and aggregation; cytoskeleton organization; RNA processing and stability; and autophagy regulation $[17,18]$.

Acetylation of lysine residues can be catalyzed by KATs or modified by abundant Ac-CoA through nonenzymatic mechanisms. Conversely, lysine deacetylation is catalyzed by KDACs, which comprise two major groups with distinct catalytic mechanisms: $\mathrm{NAD}^{+}$-dependent Sirtuins (SIRTs) and $\mathrm{Zn}^{2+}$-dependent histone deacetylases (HDACs) (Figure 1). The acetylation levels of lysines are highly dynamic, and the balance between lysine acetylation and deacetylation is precisely controlled by KATs and KDACs as well as by the concentration of Ac-CoA in organellar compartments such as mitochondria $[19,20]$.

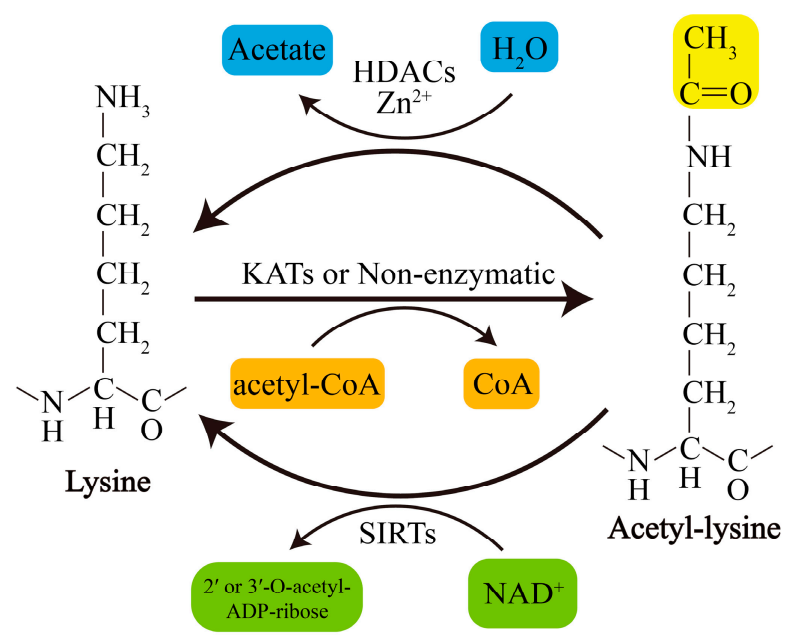

Figure 1. Schematic overview of lysine acetylation and deacetylation. Lysine acetylation, which is catalyzed by KATs, involves transfer of an acetyl group from Ac-CoA to the $\varepsilon$-amino side chain of lysine or occurs nonenzymatically. Deacetylation of lysine residues is catalyzed by $\mathrm{Zn} 2^{+}$-dependent HDACs or by $\mathrm{NAD}^{+}$-dependent SIRTs. $\mathrm{NAD}^{+}$, nicotinamide adenine dinucleotide.

\subsection{KATs and KDACs in Humans and Their Involvement in PD}

To date, at least 22 human KATs have been identified to display acetyltransferase activity; these KATs can be divided into three major families: the MYST family, the GNAT family, and the p300/CBP family [18,21] (Table 2). The substrate specificity of KATs is primarily determined by their subcellular distribution or interacting partners or by the availability of lysine in substrates [17]. Most KATs are localized mainly in the nucleus, where they mediate processes including but not limited to histone acetylation, and some KATs also located in the cytoplasm are responsible for cytoplasmic substrate acetylation [17]. Recently, GCN5-like 1 (GCN5L1) and Ac-CoA Acetyltransferase 1 (ACAT1) 
were identified as mitochondrial KATs that regulate mitochondrial functions by acetylating several mitochondrial substrates [22,23]. In addition, the well-known nuclear KAT8/MOF is also found to localize to mitochondria and affect mitochondrial functions [24]. The classifications, subcellular localization, involvement in PD models, and relevant substrates of these KATs are presented in Table 2. However, to date, only a small proportion of KATs have been identified to be related to PD (Table 2).

Table 2. Human KATs and their Involvement in PD.

\begin{tabular}{|c|c|c|c|}
\hline Family & Name & $\begin{array}{l}\text { Subcellular } \\
\text { Localization }\end{array}$ & $\begin{array}{c}\text { PD Model/KAT Change/Substrate } \\
\text { Acetylation Changes }\end{array}$ \\
\hline GNAT & KAT1/HAT1 & Nucleus & Mn/expression $\downarrow / \mathrm{H} 3$ and $\mathrm{H} 4 \downarrow[25]$. \\
\hline GNAT & KAT2A/GCN5 & Nucleus & $\mathrm{MPP}^{+} /$activity $\uparrow / \mathrm{PGC}-1 \alpha \uparrow[26]$. \\
\hline GNAT & KAT2B/PCAF & Nucleus & NA \\
\hline GNAT & KAT9/ELP3 & Nucleus/cytoplasm & NA \\
\hline GNAT & $\alpha \mathrm{TAT} 1 / \mathrm{ATAT} 1$ & Cytoplasm/membrane & $\begin{array}{c}\text { LRRK2 knockout/NA/ } \alpha \text {-tubulin } \uparrow ; \\
\text { LRKK2 R1441C or } \\
\text { Y1699C/NA/ } \alpha \text {-tubulin } \downarrow[27,28] .\end{array}$ \\
\hline p300/CBP & КАТЗА/СBP & Nucleus/cytoplasm & Dieldrin/expression $\uparrow / \mathrm{H} 3$ and $\mathrm{H} 4 \uparrow$ [29]. \\
\hline p300/CBP & KAT3B/p300 & Nucleus/cytoplasm & $\begin{array}{l}\alpha \text {-syn/expression and activity } \\
\downarrow / \mathrm{NF}-\kappa \mathrm{B}-\mathrm{p} 65 \text { or } \mathrm{H} 3 \downarrow[30,31] .\end{array}$ \\
\hline MYST & KAT5/TIP60/PLIP & Nucleus/cytoplasm & NA \\
\hline MYST & KAT6A/MOZ/MYST3 & Nucleus & NA \\
\hline MYST & KAT6A/MORF/MYST4 & Nucleus & NA \\
\hline MYST & KAT7/HBO1/MYST2 & Nucleus & NA \\
\hline MYST & KAT8/MOF/MYST1 & Nucleus/mitochondria & NA \\
\hline Other & KAT4/TAF1/TAFII250 & Nucleus & NA \\
\hline Other & KAT12/TFIIC90 & Nucleus & NA \\
\hline Other & KAT13A/SRC-1/NCOA1 & Nucleus & NA \\
\hline Other & KAT13B/SRC-3/NCOA3 & Nucleus/cytoplasm & NA \\
\hline Other & KAT13C/SRC-2/NCOA2 & Nucleus & NA \\
\hline Other & KAT13D/CLOCK & Nucleus/cytoplasm & NA \\
\hline Other & ATF-2/CREB2 & Nucleus/cytoplasm & NA \\
\hline Other & NAT10 & Nucleus & NA \\
\hline Other & ACAT1 & Mitochondria & NA \\
\hline Other & GCN5L1 & Mitochondria & NA \\
\hline
\end{tabular}

$\uparrow$, upregulation; $\downarrow$, downregulated; NA, not available; PGC- $1 \alpha$, peroxisome proliferator-activated receptor $\gamma$ coactivator- $1 \alpha$; NF- $\mathrm{BB}$, nuclear factor Kappa-B.

KDACs, originally referred to HDACs, were initially discovered to deacetylate histones in 1995 [32]. Later, they were also found to regulate nonhistone protein acetylation and cellular functions [33]. Currently, KDACs are grouped into two major types: NAD ${ }^{+}$-dependent SIRTs (SIRT1-7) and $\mathrm{Zn}^{2+}$-dependent HDACs (HDAC1-11). They can also be divided into four categories according to phylogeny and sequence similarities: Class I, Class IIa, Class IIb, and Class IV (Table 2). Recently, lymphoid enhancer-binding factor 1 (LEF1) and T cell-specific transcription factor 1 (TCF1) were identified as novel KDACs that are not related to the abovementioned types of KDACs [34]. $\mathrm{Zn}^{2+}$-dependent HDACs are primarily distributed in the nucleus or cytoplasm, although HDAC1 and HDAC7 are also found in mitochondria in some types of cells or under certain conditions [35,36]. In contrast, some SIRTs, including SIRT3-5, are restricted to the mitochondria, indicating their unique and crucial roles in mitochondria. However, it should be noted that several KDACs, such as that of SIRT4-6 and some class IIa HDACs, display weak or no deacetylase activity or target other types of acylation [17]. For example, SIRT5 exerts the activity of desuccinylase, demalonylase, and deglutarylase [37]; SIRT4 removes the acyl moieties from lysine residues such as methylglutaryl-, hydroxymethylglutaryland 3-methylglutaconyl-lysine [38]; SIRT6 functions to deacetylate long-chain fatty acyl groups rather than protein deacetylation [39]; The classifications, subcellular localization of KDACs, as well as their involvement in PD and the relevant acetylation of substrates are presented in Table 3. 
Interestingly, the activity or expression levels of nuclear SIRT1 and mitochondrial SIRT3 are consistently decreased in PD tissues and different PD models. The activity or expression levels of nuclear HDAC2 and HDAC3 are increased in most PD models, but the expression levels of HDAC2 are decreased in tissues of PD patients. Furthermore, the activity or expression levels of two main cytoplasmic KDACs, HDAC6 and SIRT2, are downregulated and upregulated in most PD models, respectively (Table 3). Of note, beyond acetylation, several KATs/KDACs have activity of other acylation modifications including propionyl, butyryl, 2-hydroxyisobutyryl, crotonyl, malonyl, succinyl, or glutaryl modification. For example, p300 has crotonyltransferase activity [40], while KAT2A/GCN5 has both crotonyltransferase and uccinyltransferase activity [41,42], whereas HDAC1/2/3/8 and SIRT1-3 possess decrotonylating activity [43-45]. Whether these changes in KATs or KDACs in PD patients or models also cause variation of other acylation modifications, and the roles of these acylation variations in PD pathology, deserve further research.

Table 3. Human KDACs and their Involvement in PD.

\begin{tabular}{|c|c|c|c|}
\hline Class & Name & $\begin{array}{l}\text { Subcellular } \\
\text { Localization }\end{array}$ & PD Model/KDAC Change/Substrate Acetylation Level Change \\
\hline I & HDAC1 & Nucleus & $\begin{array}{l}\text { Patient tissues, MPTP or MPP }+ \text { /expression } \downarrow / \mathrm{H} 2 \mathrm{~A}, \mathrm{H} 2 \mathrm{~B}, \mathrm{H} 3 \text { and } \mathrm{H} 4 \uparrow[46] \text {. } \\
\text { Patient tissues, MPTP or } \mathrm{MPP}^{+} / \text {expression } \downarrow / \mathrm{H} 2 \mathrm{~A}, \mathrm{H} 2 \mathrm{~B}, \mathrm{H} 3 \text { and } \mathrm{H} 4 \uparrow[46]\end{array}$ \\
\hline I & HDAC2 & Nucleus & $\begin{array}{l}\mathrm{MPP}^{+} / \text {expression } \uparrow / \mathrm{NA}[47] \text {; idiopathic PD fibroblasts/expression } \uparrow / \mathrm{H} 3 \downarrow \text {; } \\
\text { LRRK2 G2109S PD fibroblasts/expression } \uparrow / \mathrm{H} 3 \downarrow[48] .\end{array}$ \\
\hline I & HDAC3 & Nucleus & $\begin{array}{c}\text { Idiopathic PD fibroblasts/expression } \uparrow / \mathrm{H} 3 \downarrow[48] \text {; Mn/expression } \uparrow / \mathrm{H} 3 \\
\text { and H4 } \downarrow \text { [25]; LRRK2 or mutation/phosphorylation } \uparrow \text {, nuclear } \\
\text { translocation } \uparrow \text { and activity } \uparrow / \mathrm{H} 4 \downarrow[49] ; \\
\text { PINK1 mutation/phosphorylation } \downarrow \text { and activity } \downarrow / \mathrm{p} 53 \uparrow[50] .\end{array}$ \\
\hline I & HDAC8 & Nucleus/cytoplasm & NA \\
\hline IIa & HDAC4 & Nucleus/cytoplasm & $\begin{array}{c}\text { Patient tissues, MPTP or } \mathrm{MPP}^{+} / \text {expression } \downarrow / \mathrm{H} 2 \mathrm{~A}, \mathrm{H} 2 \mathrm{~B}, \mathrm{H} 3 \text { and } \mathrm{H} 4 \uparrow[46] \\
\text { paraquat/expression } \downarrow / \mathrm{H} 3 \uparrow[51,52] \text {; idiopathic PD } \\
\text { fibroblasts/expression } \uparrow / \mathrm{H} 3 \downarrow, L R R K 2 \mathrm{G} 2109 \mathrm{~S} \mathrm{PD} \\
\text { fibroblasts/expression } \uparrow / \mathrm{H} 3 \downarrow[48] \text {; Mn/expression } \uparrow / \mathrm{H} 3 \text { and H4 } \downarrow \text { [25]. }\end{array}$ \\
\hline IIa & HDAC5 & Nucleus/cytoplasm & NA \\
\hline IIa & HDAC7 & Nucleus/cytoplasm & Paraquat/expression $\downarrow / \mathrm{H} 3 \uparrow[51,52]$. \\
\hline IIa & HDAC9 & Nucleus/cytoplasm & NA \\
\hline $\mathrm{IIb}$ & HDAC6 & Primarily cytoplasm & $\begin{array}{l}\text { Patient tissues, MPTP or MPP } / \text { expression } \downarrow \text { [46]; idiopathic PD } \\
\text { fibroblasts/expression } \downarrow, L R R K 2 \text { G2109S PD fibroblasts/expression } \downarrow \text { [48]; } \\
\text { Parkin absence/NA/ } \alpha \text {-tubulin } \uparrow[53] \text {; ATP13A absence/activity } \downarrow \\
\text { / } \alpha \text {-tubulin } \uparrow[54] ; \text { 6-OHDA/expression } \uparrow / \text { peroxiredoxin } 1 / 2 \downarrow[55] \text {. }\end{array}$ \\
\hline $\mathrm{IIb}$ & HDAC10 & Primarily cytoplasm & NA \\
\hline III & SIRT1 & Nucleus & 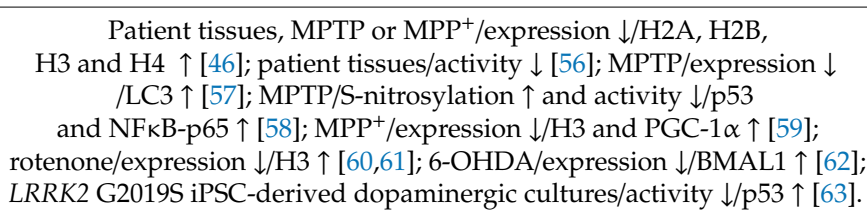 \\
\hline III & SIRT2 & Cytoplasm & $\begin{array}{l}\text { MPTP/activity } \uparrow / \alpha \text {-syn } \downarrow[64] ; \alpha \text {-syn/activity } \uparrow / \alpha \text {-tubulin } \downarrow \text { [65]; MPTP or } \\
\mathrm{MPP}^{+} / \text {activity } \uparrow / \text { Foxo3a } \downarrow[66] ; 6 \text {-OHDA/activity } \downarrow / \alpha \text {-tubulin } \uparrow \text { [67]. }\end{array}$ \\
\hline III & SIRT3 & Mitochondria & $\begin{array}{c}\text { Patients/NA/MnSOD } \uparrow[68] \text {; MPTP/expression } \downarrow / \text { SOD2 and ATP5B } \uparrow[69] ; \\
\mathrm{MPP}^{+} / \text {expression } \downarrow / \text { citrate synthase and isocitrate dehydrogenase } 2 \uparrow[70] ; \\
\alpha \text {-syn/expression } \downarrow / \text { SOD } \uparrow \uparrow[71] ; L R R K 2 \text { G2019S iPSC-derived } \\
\text { dopaminergic cultures/activity } \downarrow / S O D 2 \uparrow[63] .\end{array}$ \\
\hline III & SIRT4 & Mitochondria & NA \\
\hline III & SIRT5 & Mitochondria & NA \\
\hline III & SIRT6 & Nucleus & NA \\
\hline III & SIRT7 & Nucleolus & NA \\
\hline IV & HDAC11 & Primarily nucleus & NA \\
\hline Other & TCF1 & Nucleus & NA \\
\hline Other & LEF1 & Nucleus & NA \\
\hline
\end{tabular}

$\uparrow$, upregulation; $\downarrow$, downregulated; NA, not available, Mn, manganese; BMAL1, brain and muscle arnt-like 1; iPSC, induced pluripotent stem cells, Foxo3a, Forkhead box O3; ATP5B, ATP synthase subunit $\beta$; SOD2, superoxide dismutase. 


\section{Histone Acetylation in PD and Treatment Strategy Clues}

\subsection{Acetylation of Histones in Tissues of PD Patients}

Histones are a major group of substrates for lysine acetylation, and histone acetylation is one of the main PTMs (also including histone phosphorylation, methylation, ubiquitination, etc.) that form the "histone code"; a hypothesis states that histone PTMs alone or in combination are believed to modulate chromatin structure and functions [72]. Histone acetylation or in combination with other PTMs can recruit or repel chromatin regulatory protein complexes to control gene expression or regulate other genomic functions, thereby involving various important cellular processes and disease progression [73]. Generally, acetylation of histones by KATs weakens their binding to DNA, relaxes chromatin and generally turns on gene transcription; in contrast, deacetylation of histones by HDACs results in condensation of chromatin and turns off gene transcription [74]. In addition, histone acetylation enables its interaction with bromodomain-containing proteins and transcriptional factors, thereby increasing the number of regulatory factors [75]. Hypoacetylated state of histones promotes their binding to transcriptional co-repressors, which are recruited by specific KDACs; not only that, KDACs can also inhibit the transcription initiation or are recruited to prepare for transcription repression [21].

Park et al. found that markedly higher lysine acetylation levels of specific sites in histones, including $\mathrm{H} 2 \mathrm{~A}, \mathrm{H} 2 \mathrm{~B}, \mathrm{H} 3$, and $\mathrm{H} 4$, are present in DA neurons from midbrain tissues of PD patients compared with matched controls [46]. The upregulation of histone acetylation is probably caused by the downregulation of KDACs, including HDAC1, HDAC2, HDAC4, HDAC6, and SIRT1, without significant changes in several KATs, including CBP, TIP60, and GCN5 [46]. Another study has indicated that increased H3 acetylation is mainly due to increased H3K14 and H3K18 acetylation in the postmortem PD primary motor cortex [76]. In addition, increases in histone acetylation are disease-dependently associated with PD progression [77].

Recently, a comparative study was conducted between two groups of fibroblasts from idiopathic PD and genetic PDLRRK2 G2109S patients [48,78]. Mutations in the LRRK2 gene, including G2109S and R1441G, account for an autosomal dominant type of familial PD [10]. Although the acetylation levels of total proteins in idiopathic PD fibroblasts compared with controls are increased, the acetylation levels of histones are decreased. Interestingly, the non-specific HDAC inhibitor trichostatin A (TSA) is harmful for idiopathic PD fibroblasts, while the histone acetyltransferase (HAT) inhibitor anacardic acid (AA) is beneficial [48]. The hyperacetylation of proteins in idiopathic PD cells may be due to mitophagy dysfunction and damaged mitochondrial accumulation that decreases $\mathrm{NAD}^{+}$generation, which consequently reduces the activity of SIRTs. SIRT inhibition triggers an increase in the activity of class I and II KDACs, including HDAC2, HDAC3, and HDAC4, but decreases total HDAC activity, especially HDAC6 activity $[48,78,79]$. Therefore, HAT inhibitors or selective inhibitors targeting HDAC2, HDAC3, or HDAC4 are better than nonspecific HDAC inhibitors at restoring the balance of the acetylation levels of histones and reducing cell damage in PD.

There have been very large inconsistencies in histone acetylation and related enzyme changes in PD patient samples in these studies. The numbers of clinical samples may have been insufficient to reflect the actual changes in histone acetylation and KATs/KDACs. More clinical samples and more detailed mechanistic studies are needed in the future, especially studies in which specific KATs and KDACs are varied and the changes in histone acetylation are investigated in PD patients.

\subsection{PD-Related Neurotoxins and Acetylation of Histones}

$\mathrm{H} 3$ or $\mathrm{H} 4$ hyperacetylation is a key epigenetic change in DA neurons exposed to other PD-related neurotoxins, such as MPTP/MPP ${ }^{+}$, dieldrin, rotenone, and paraquat. For example, MPTP treatment in mice or $\mathrm{MPP}^{+}$treatment in neuronal cells leads to increased lysine acetylation of histones, with corresponding decreases in HDAC1, HDAC2, HDAC4, HDAC6, and SIRT1 levels [46]. $\mathrm{MPP}^{+}$treatment decreases SIRT1 expression and promotes acetylation of H3K14, which activates the hypoxia inducible factor $1 \alpha(H I F-1 \alpha)$ promoter to induce its transcription [59]. Consistent with 
the findings of this study, an increase in $\mathrm{H} 3$ acetylation in the striatum has also been found in mice treated with MPTP [80]. Pharmacological inhibition of HATs with the inhibitor garcinol suppresses $\mathrm{MPP}^{+}$-induced cell death, whereas $\mathrm{HDAC1} / 2$ genetic inhibition or treatment with the HDAC inhibitors MS-275 and TSA exacerbates cell damage [46]. However, another study has indicated that MPTP/MPP ${ }^{+}$increases HDAC2 expression and that the HDAC1/2-specific inhibitor K560 attenuates MPTP/MPP ${ }^{+}$-induced neuronal cell death [47]. Interestingly, the pan-HDAC inhibitors TSA and hydroxamic acid (SAHA) do not inhibit $\mathrm{MPP}^{+}$-induced cell death, but valproate (VPA) exacerbates $\mathrm{MPP}^{+}$-induced cell death in vitro [47]. These results indicate that MPTP/MPP ${ }^{+}$widely inhibits the expression of KDACs, and this inhibition may be accompanied by compensatory upregulation of individual HDACs under certain conditions.

Dieldrin, a toxin implicated in PD pathogenesis, induces $\mathrm{H} 3$ and $\mathrm{H} 4$ hyperacetylation in a time-dependent manner with CBP accumulation, and hyperacetylation modification is an early event in dieldrin-induced neurotoxicity [29]. Moreover, the HAT inhibitor AA dramatically attenuates dieldrin-mediated DA neuronal death [29]. Paraquat stimulates H3 rather than H4 hyperacetylation, which contributes to the death of DA neuronal cells, while paraquat-induced histone acetylation is related to decreases in the expression levels of HDAC4 and HDAC7 [51,52]. Rotenone increases H3K9 acetylation by reducing SIRT1 levels and thus activates p53 expression to promote neurodegeneration [60]. Resveratrol, a SIRT1 activator, attenuates rotenone-induced cell damage and p53 expression [60]. HAT inhibitors such as garcinol, AA, and curcumin reduce L-DOPA-induced dyskinesia in 6-OHDA-induced PD mouse models, suggesting that L-DOPA combined with a HAT inhibitor may have therapeutic potential for L-DOPA-induced dyskinesia in PD patients [81].

Manganese (Mn) neurotoxicity is tightly associated with Parkinson's-like symptoms; however, unlike the above neurotoxins, $\mathrm{MnCl}_{2}$ significantly suppresses the acetylation of $\mathrm{H} 3$ and $\mathrm{H} 4$ in neuronal cells in a time-dependent manner while increasing the expression of HDAC $3 / 4$ and decreasing the expression of HAT [25]. In addition, the HAT inhibitor AA facilitates Mn-induced neuronal apoptosis, and HDAC inhibition by TSA has a neuroprotective effect [25]. Mn also induces a reduction in histone acetylation in astrocytes and inhibits the expression of astrocytic glutamate aspartate transporter (GLAST) and glutamate transporter 1 (GLT-1), which further contribute to neurotoxicity [82]. The HDAC inhibitor VPA reverses the Mn-induced reduction in histone acetylation, attenuates the Mn-induced decrease in astrocytic glutamate transporter expression, and reverses Mn-induced DA neurotoxicity [82].

It can be seen that several modulators of KATs or KDACs have inconsistent or even completely opposite effects in PD models. The reason may be that many HDAC and HAT modulators used in the above studies may have non-specific effects besides affecting enzyme activity and therefore have other effects on cellular function. For example, the HAT inhibitor garcinol also possesses antioxidant, anti-inflammatory, and neuroprotective properties, as well as inducing DNA damage and growth arrest in cancer cells $[83,84]$. Similarly, beyond inhibiting KAT activity, curcumin also has antioxidant, anti-inflammatory, and anti-tumor activity by affecting multiple enzymes [85]. Therefore, more specific inhibitors or activators targeting KATs or KDACs need to be selected to explore the role of histone acetylation in various PD models.

Nevertheless, the evidence indicates that histones are hypoacetylated or hyperacetylated in response to distinct PD-related neurotoxins. For example, MPTP/MPP ${ }^{+}$, dieldrin, paraquat, and rotenone all induce $\mathrm{H} 3$ or $\mathrm{H} 4$ hyperacetylation by decreasing the expression of KDACs, including several HDACs and SIRT1 (Figure 2), indicating that HAT inhibitors or SIRT1 activators are potential therapeutics for the balance of histone lysine acetylation and inhibition of neurotoxin-induced neurotoxicity. However, Mn leads to hypoacetylation of $\mathrm{H} 3$ and H4, suggesting that HDAC inhibitors may be valuable and effective treatment agents for Mn-induced PD neurotoxicity.

\subsection{PD-Related Genes and Acetylation of Histones}

Several products of PD-related genes have been shown to affect histone acetylation or to be regulated by histone acetylation [86]. $\alpha$-syn plays vital roles in PD pathogenesis, as indicated by findings 
that $\alpha$-syn aggregation in LBs in most PD cases and point mutations, duplications, or triplications of the PARK1/SNCA gene, which encodes $\alpha$-syn, cause autosomal dominant familial forms of PD $[87,88]$. $\alpha$-syn may cause neurotoxicity by interacting with histones to alter their acetylation. Binding of $\alpha$-syn to histones in the nucleus of SNpc neurons promotes its fibrillation and toxicity [89]. Increased $\alpha$-syn expression results in a reduction in $\mathrm{H} 3$ acetylation, and treatment with the HDAC inhibitor sodium butyrate $(\mathrm{NaB})$ reverses $\alpha$-syn-induced DNA damage [31]. Furthermore, $\alpha$-syn reduces $\mathrm{H} 3$ acetylation, and the PD-related $\alpha$-syn mutants A30P and A53T may aggravate this effect [90]. The HDAC inhibitors $\mathrm{NaB}$ and SAHA protect against $\alpha$-syn-mediated neurotoxicity in both cellular and transgenic Drosophila models [90]. The HDAC inhibitor VPA has also been shown to protect against $\alpha$-syn-mediated neurotoxicity in rat PD models [91]. Of note, there is no direct association between $\alpha$-syn and $\mathrm{H} 3$, indicating that the reduction in histone acetylation caused by $\alpha$-syn may occur through histone masking [92]. Through a similar mechanism, nuclear $\alpha$-syn binds to the gene promoter region of peroxisome proliferator-activated receptor $\gamma$ coactivator- $1 \alpha$ (PGC-1 $\alpha$ ), a mitochondrial transcription factor whose dysfunction contributes to mitochondrial dysfunction and oxidative stress in PD pathogenesis; prevents histone acetylation; and represses PGC- $1 \alpha$ expression [93]. $\alpha$-syn also decreases histone acetylation, probably by reducing p300 levels and its HAT activity [30].

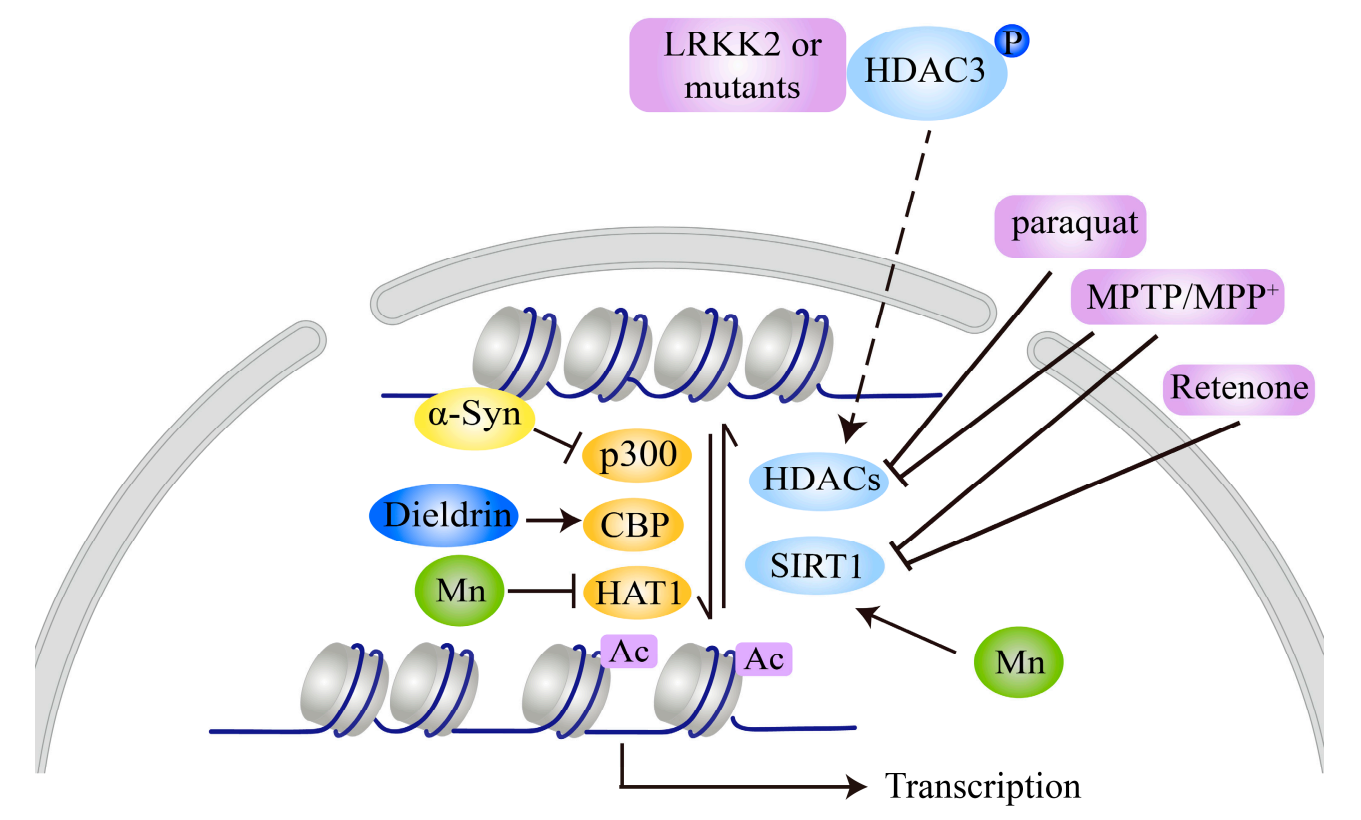

Figure 2. Lysine acetylation of histones mediated by PD-related neurotoxins and genetic factors. $\mathrm{MPTP} / \mathrm{MPP}^{+}$, rotenone, paraquat, or dieldrin treatment leads to hyperacetylation of $\mathrm{H} 3$ and/or H4 by decreasing the activity or expression of certain HDACs or SIRT1 or by increasing CBP expression. $\alpha$-syn causes hypoacetylation of $\mathrm{H} 3$ by binding to histones or inhibiting p300 expression and activity. LRKK2 or its mutants repress $\mathrm{H} 4$ acetylation by phosphorylating HDAC3 and promoting its nuclear translocation to increase its activity. Mn decreases $\mathrm{H} 3$ and $\mathrm{H} 4$ acetylation by increasing HDAC3/4 expression and decreasing HAT1 expression, respectively.

LRRK2 phosphorylates HDAC3 at S424 and stimulates its deacetylase activity through an interaction, subsequently promoting deacetylation of $\mathrm{H} 4 \mathrm{~K} 5 / \mathrm{H} 4 \mathrm{~K} 12$ and leading to repression of gene transcription. LRRK2 also promotes the nuclear translocation of HDAC3 by phosphorylating karyopherin subunits $\alpha 2$ and $\alpha 6$ [49]. The phosphorylation and nuclear translocation of HDAC 3 are further increased under 6-OHDA treatment, and LRRK2 ultimately promotes 6-OHDA-induced damage by positively modulating HDAC3 [49]. The HDAC inhibitor VPA improves motor and nonmotor behaviors in PD mice harboring the LRRK2 R1441G mutation. VPA administration also increases the levels of histone acetylation and the numbers of DA neurons in the SNpc in transgenic mice [94]. 
Interestingly, in contrast to $\mathrm{MPTP} / \mathrm{MPP}^{+}$, dieldrin, paraquat, and rotenone, and similar to Mn, $\alpha$-syn and LRRK2 lead to hypoacetylation of H3 or H4. $\alpha$-syn inhibits histone acetylation by binding to histones or decreasing p300 expression, while LRKK2 and its pathogenic mutants reduce histone acetylation by promoting HDAC 3 phosphorylation and nuclear translocation to increase its deacetylase activity (Figure 2), suggesting that HDAC inhibitors may be valuable and effective for $\alpha$-syn-, LRRK2-, or Mn-induced PD neurotoxicity. However, whether other genetic factors have effects on histone acetylation still lacks experimental evidence. These pathogenic factors, such as genetic factors ( $\alpha$-syn and LRRK2) and environmental toxins, have similar or different effects on histone acetylation, which may be related to their involvement in general or specific cellular signals/functions in nerve cells [10,95]. Recently, Mn has been shown to promote $\alpha$-syn aggregation and transmission [96], which may contribute to hypoacetylation of histones, similar to the direct effect of $\alpha$-syn on histone acetylation. More detailed studies are needed to clarify the mechanisms for these differences, which will promote the discovery of the role of histone acetylation in PD pathology and be beneficial for choosing appropriate KAT or KDAC modulators for treatment of different PD models.

Furthermore, $\alpha$-syn expression may also be regulated by histone acetylation. Voutsinas et al. found that epigenetic silencing of the A53T mutant allele involves histone deacetylation modification, as the use of an HDAC inhibitor can reactivate allele expression [97]. Consistent with this finding, H3K27 acetylation-enriched enhancer regions have been identified at the SNCA gene locus [98]. These results indicate that $\alpha$-syn expression may also be regulated by histone acetylation. MPTP increases the levels of $\alpha$-syn, which is involved in the activation of proteinase-activated receptor $2 / \mathrm{NF}-\mathrm{kB}$ signaling and $\mathrm{H} 3$ acetylation in the $\alpha$-syngene promoter region [99].

\section{Lysine Acetylation of Nonhistone Proteins in PD Pathogenesis}

In addition to changes in acetylation of histones, accumulating evidence suggests that imbalance between acetylation and deacetylation modifications on nonhistone proteins is also associated with the pathogenesis of PD.

\subsection{PD-Related Genes and Nonhistone Acetylation}

Interestingly, $\alpha$-syn itself can be acetylated and deacetylated, and its deacetylation status mediates its neurotoxicity. In addition to $\mathrm{N}$-terminal acetylation of $\alpha$-syn, an irreversible modification, lysine acetylation of $\alpha$-syn is an important mechanism for regulation of its aggregation and neurotoxicity [100-103]. $\alpha$-syn can be acetylated at K6 and K10 to inhibit its aggregation and toxicity, and these modifications are reversed by SIRT2 (Figure 3A). SIRT2 deletion promotes $\alpha$-syn acetylation and protects against $\alpha$-syn- or MPTP-induced neuronal toxicity in vivo [64]. Treatment with the SIRT2 inhibitor AGK2 and genetic inhibition of AK-1 or SIRT2 also alleviates $\alpha$-syn-mediated DA neuronal loss both in vitro and in a Drosophila PD model [104].

Furthermore, $\alpha$-syn also has an inhibitory effect on the acetylation of $\alpha$-tubulin via a SIRT2-related mechanism, impairing microtubule (MT) stability and contributing to PD pathology (Figure 3A), and the SIRT2 inhibitor AK-1 partially reverses the reduction in acetylation of $\alpha$-tubulin mediated by $\alpha$-syn and restores MT stability [65]. In addition, deacetylated $\alpha$-tubulin interacts with $\alpha$-syn oligomers to form a toxic complex [105]. Although HDAC6 also deacetylates $\alpha$-tubulin and HDAC6 inhibition protects DA neurons from $\alpha$-syn toxicity in a rat model of PD [106], depletion of HDAC6 significantly enhances $\alpha$-syn-induced DA neuron loss and locomotor dysfunction in PD models [107,108]. HDAC6 also increases in expression and colocalizes with $\alpha$-syn in the perinuclear region to form aggresome-like bodies and inhibit its neurotoxicity through a mechanism involving the aggresome-autophagy pathway [109]. These results suggest that SIRT2-mediated $\alpha$-tubulin deacetylation plays essential roles in $\alpha$-syn-mediated PD pathogenesis and that targeting SIRT2 inhibition rather than HDAC6 inhibition is a potential therapeutic strategy for $\alpha$-syn-related PD.

LRRK2 directly interacts with $\beta$-tubulins and has an inhibitory effect on K40 acetylation of $\alpha$-tubulin and a dramatic positive effect on $\alpha$-tubulin acetylation in mouse embryonic fibroblasts derived from 
LRRK2-knockout mice [28]. Interestingly, LRRK2 mutants have been found to preferentially bind to deacetylated MTs, disrupt axonal transport in neurons, and cause locomotor deficits in a PD Drosophila model (Figure 3A) [27]. Increases in MT acetylation caused by the $\alpha$-tubulin acetyltransferase $\alpha$ TAT1 or deacetylase inhibitors prevent the interaction between LRRK2 mutants and MTs, and genetic inhibition of HDAC6 or SIRT2 or administration of the SIRT2 inhibitor AGK2 reverses the defective axonal transport and locomotor behavior induced by LRRK2 mutants [27], indicating that deacetylase inhibitors targeting HDAC6 or SIRT2 are potential therapeutics for axonal transport dysfunction in mutant LRRK2-related PD.

A

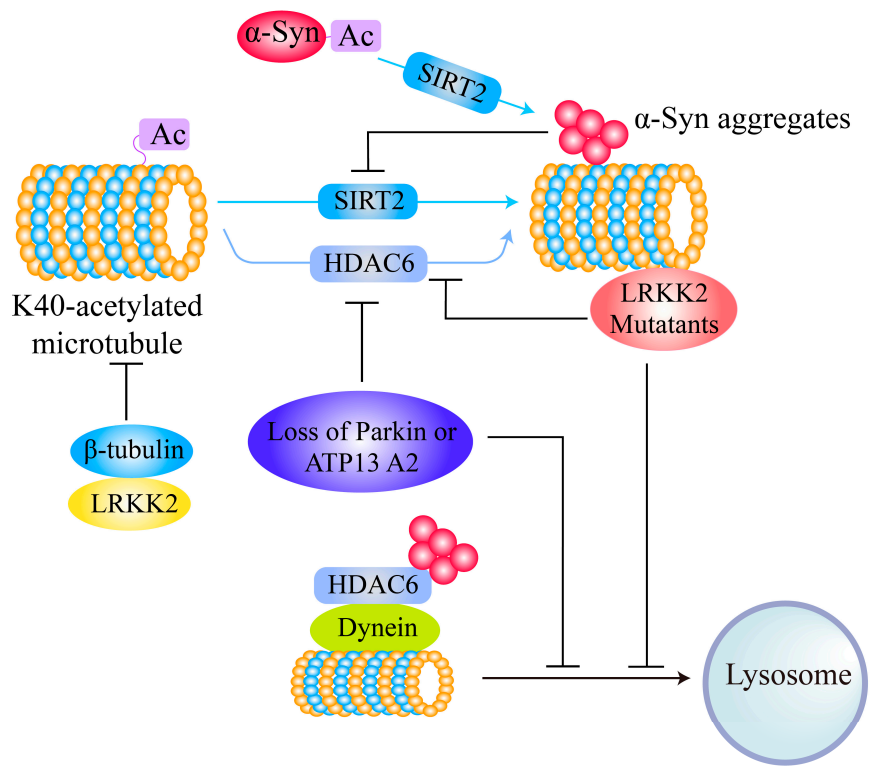

$\mathrm{B}$

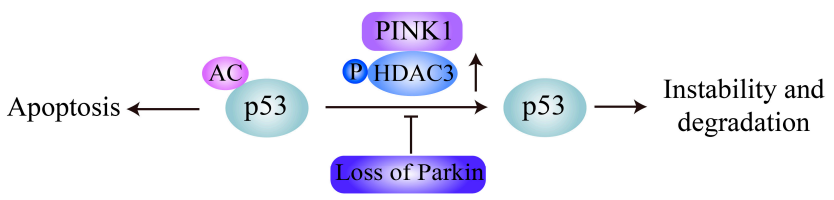

Figure 3. Acetylation of $\alpha$-tubulin or p53 is affected by PD-related genetic factors. (A) Deacetylation of $\alpha$-syn by SIRT2 facilitates its aggregation and toxicity. $\alpha$-syn activates SIRT2 to inhibit acetylation of $\alpha$-tubulin, and the deacetylated $\alpha$-tubulin associates with $\alpha$-syn oligomers to form a toxic complex. LRRK2 binds to $\beta$-tubulins and inhibits $\alpha$-tubulin acetylation, and LRKK2 mutants preferentially bind to deacetylated MTs and disrupt axonal transport. However, loss of Parkin or ATP13A2 leads to repression of HDAC6, hyperacetylation of $\alpha$-tubulin, and dysfunction of aggregate degradation. (B) PINK1 phosphorylates HDAC3 to increase its p53-deacetylating activity, and deacetylated p53 is unstable. Loss of PINK1 leads to hyperacetylation of p53 and thus induces neuronal cell damage.

Loss of Parkin (encoded by the PARK2 gene mutations which cause early-onset autosomal recessive familial PD) induces hyperacetylation of MTs in both DA neuron cell bodies and fibers and disrupts MT stability [53]. On the other hand, deacetylase activity of HDAC6 directed toward $\alpha$-tubulin is required for Parkin movement and accumulation in the centrosome [110] and promotes mitophagy [111]. Similarly, cells and Drosophila melanogaster and mouse tissues with loss of ATP13A2, encoded by the PARK9 gene (mutations in which are also related to the early-onset autosomal recessive form of familial PD) exhibit increased acetylation of $\alpha$-tubulin and cortactin and impaired autophagosome-lysosome fusion, 
which are associated with reduced lysosomal localization and activity of HDAC6 (Figure 3A). In addition, wild-type HDAC6, but not a deacetylase-inactive mutant, antagonizes hyperacetylation and restores autophagosome-lysosome fusion [54], indicating that reduced activity of HDAC6 deacetylase is an essential pathological factor related to impaired autophagy flux in PD pathogenesis. Activation or overexpression of HDAC6 is thus a potential therapeutic strategy for Parkin- or ATP13A2-related PD.

Another PD-related protein, PINK1, is encoded by the PINK1/PARK6 gene, mutations in which cause autosomal recessive early-onset PD [112,113]; this protein has been shown to bind to HDAC3 and increase its histone deacetylase activity via phosphorylation in neuronal cells [50]. HDAC 3 phosphorylated by PINK1 binds to $\mathrm{p} 53$, decreases $\mathrm{p} 53$ acetylation and stability, and thus inhibits p53-mediated neuronal cell damage (Figure 3B), and HDAC3 deficiency abolishes the effect of PINK1 on p53 [50]. Interestingly, PD-related PINK1 mutations cause PINK1 to lose the ability to influence HDAC3 deacetylase activity and increase susceptibility to p53-mediated neurodegeneration [50].

Therefore, changes in $\alpha$-tubulin acetylation are common pathologies mediated by PD-related genetic factors. $\alpha$-tubulin acetylation is a reversible modification affecting cytoskeletal organization and can be reversed by HDAC6 or SIRT2 $[17,114,115]$. PD-related gene products such as $\alpha$-syn, LRKK2, Parkin, and ATP13A all have inhibitory effects on K40 acetylation of $\alpha$-tubulin (Figure 3). However, the underlying mechanisms of treatment strategies targeting abnormal tubulin acetylation caused by these gene products are very different. Considering the gain-of-function mutations of $\alpha$-syn and LRKK2 in PD and the contribution of deacetylated $\alpha$-tubulin to their neurotoxicity, as well as the role of HDAC6 in protein aggregate degradation and autophagy [116], targeting SIRT2 inhibition may be a valuable potential therapeutic strategy for $\alpha$-syn- or LRKK2-related PD. In addition, HDAC6 activation is a potential therapeutic strategy for PD induced by loss of function of Parkin or by ATP13A2 mutation.

\subsection{PD-Related Neurotoxins and Nonhistone Acetylation}

MPTP treatment decreases SIRT1 expression and subsequently increases acetylation of MT-associated protein 1 light chain 3 (LC3), thus inhibiting autophagic degradation of $\alpha$-syn and leading to neurodegeneration of DA neurons (Figure 4). Resveratrol activates SIRT1 and deacetylates LC3 to relocalize it to the cytoplasm for $\alpha$-syn degradation by autophagy [57]. MPTP administration in mice also increases S-nitrosylation of SIRT1 and leads to inhibition of its deacetylase activity, subsequently resulting in hyperacetylation and activation of p53 and NF- $\mathrm{kB}$ subunit p65. Activation of p53 and p65 promotes neuronal apoptosis and increases glial proinflammatory gene expression, respectively (Figure 4), both of which are related to PD pathogenesis [58]. Deacetylation of Foxo3a by SIRT2 is stimulated by MPTP or MPP ${ }^{+}$treatment and increases Bim expression, thus contributing to $\mathrm{MPTP} / \mathrm{MPP}^{+}$-induced neuronal apoptosis in PD models. In addition, neurodegeneration induced by MPTP can be prevented by SIRT2 inhibition [66] as well as by SIRT1 overexpression [56].

In addition, PGC- $1 \alpha$, which plays essential roles in mitochondrial biogenesis, metabolism, and oxidative stress, has been widely implicated in PD pathogenesis [117]. PGC- $1 \alpha$ is directly acetylated by GCN5 or p300, and its acetylation results in inhibition of PGC- $1 \alpha$ transcriptional activity [118]. Increases in GCN5-mediated PGC- $1 \alpha$ acetylation contribute to MPP ${ }^{+}$-induced neuronal toxicity (Figure 4) [26]. Interestingly, SIRT1 also directly deacetylates PGC-1 $\alpha$ and enhances its functions [119]. Therapeutic reagents that inhibit GCN5 or p300 or activate SIRT1 modification may have potential value for $\mathrm{PD}$ treatment.

Furthermore, 6-OHDA treatment in cells and rats also decreases the levels of SIRT1 and results in an increased ratio of acetylated BMAL1, thus affecting the expression of circadian genes and increasing oxidative stress. An activator of SIRT1, resveratrol, decreases BMAL1 acetylation and inhibits its interaction with cryptochrome 1, thereby alleviating the impairment of antioxidant activity induced by 6-OHDA [62]. Moreover, 6-OHDA treatment significantly increases HDAC6 expression and decreases the acetylation levels of peroxiredoxin1/2, and inhibition of HDAC6 with the specific inhibitor tubastatin A increases acetylation of peroxiredoxin1/2, reduces ROS production, and ameliorates 6-OHDA 
neurotoxicity [55]. Pharmacological inhibition of HDAC6 with tubastatin A also attenuates NLRP3 inflammation in glial cells and inhibits DA neuronal degeneration while restoring the acetylation levels of peroxiredoxin2 [120]. In addition, a p300/CBP activator, CTPB, promotes the survival and neurite growth of neuronal cells and protects cells from cell death induced by 6-OHDA [121]. However, one study has indicated that 6-OHDA reduces SIRT2 activity by decreasing NAD ${ }^{+}$levels and increasing $\alpha$-tubulin acetylation and that overexpression of HDAC6 and SIRT2 reverses the changes in tubulin acetylation and MT dynamics in 6-OHDA-treated cells [67].

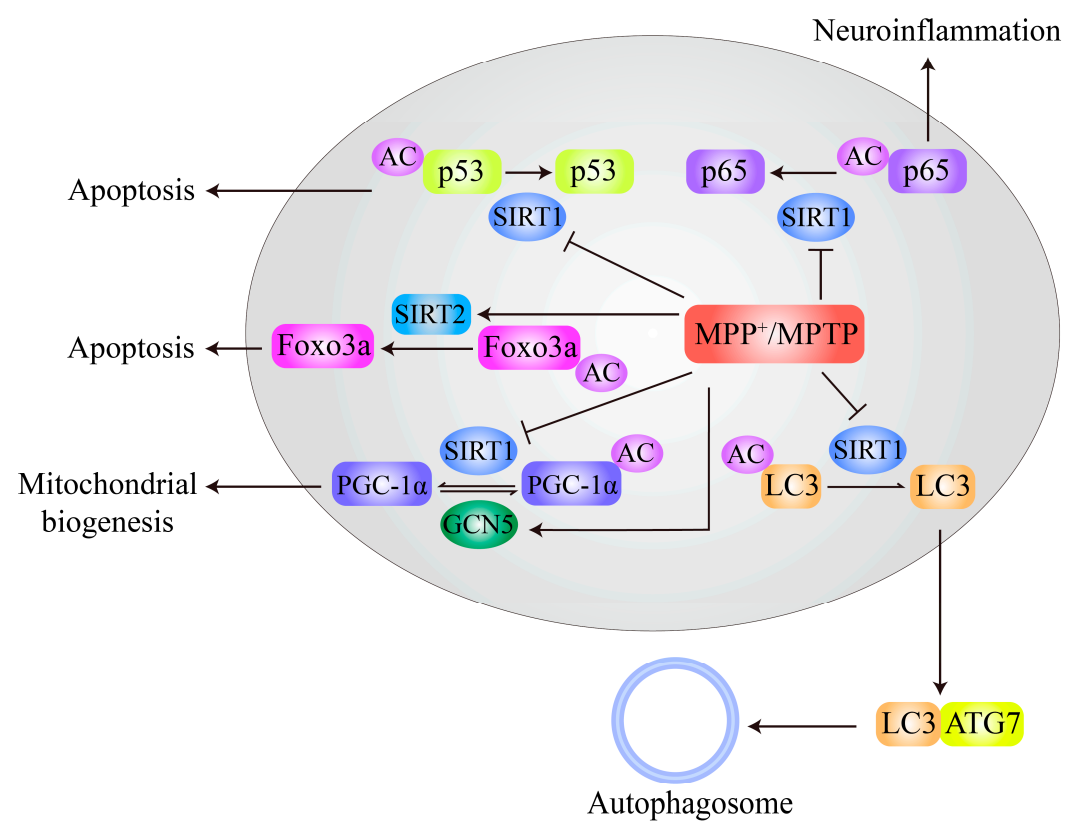

Figure 4. Effects of MPTP/MPP ${ }^{+}$on acetylation of nonhistone proteins. MPTP/MPP+ inhibits SIRT1 expression or activity to block deacetylation of various substrates, such as p53, p65, PGC- $1 \alpha$, and LC3, which leads to neuronal apoptosis, neuroinflammatory activation, mitochondrial dysfunction, and autophagy inhibition, respectively. However, MPTP/MPP+ also promotes GCN5 expression to increase PGC- $1 \alpha$ acetylation. In addition, MPTP/MPP ${ }^{+}$activates SIRT2 to induce deacetylation of Foxo3a, enhancing Bim transcription and thus leading to neurodegeneration.

Together, these findings suggest that decreased activity or expression of SIRT1 is closely related to PD pathogenesis in MPTP/MPP ${ }^{+}$- and 6-OHDA-induced PD models (Figure 4) and PD patients $[46,56]$. Interestingly, SIRT1 activation not only restores the balance of acetylation of nonhistone proteins but also reverses histone hyperacetylation-induced neuronal toxicity caused by MPTP/MPP ${ }^{+}$and rotenone. However, the correlations between PD genetic factors and SIRT1 activity or expression are still unclear.

\subsection{Acetylation of Mitochondrial Proteins in PD}

Mitochondrial dysfunction is one of the central pathogenic mechanisms of DA neuron degeneration and PD pathogenesis $[4,122]$. Mitochondrial functions are highly regulated by the dynamic acetylation modification of mitochondrial proteins [123]. With the development of acetylation proteomics techniques in recent years, it has been found that more than $60 \%$ of mitochondrial proteins contain acetylation modification sites [123]. Although mitochondrial protein acetylation is commonly recognized as nonenzymatic, mitochondrial KATs, such as ACAT1 and GCN5L1, also participate in mitochondrial protein acetylation [22,23]. However, deacetylation of mitochondrial proteins is performed mainly by SIRT3 [123,124].

Notably, neurons treated with MPTP exhibited decreased levels of the SIRT3 protein, which is responsible for the high levels of acetylation of superoxide dismutase 2 (SOD2) at the K130 site and ATP synthase $\beta$ at the K485 site, as well as loss of DA neurons (Figure 5). SIRT3 overexpression protects 
against and SIRT3 knockout promotes MPTP-induced DA neuronal loss [69]. MPP ${ }^{+}$treatment also decreases SIRT3 expression and leads to increased acetylation of citrate synthase (CS) and isocitrate dehydrogenase 2 (IDH2) and decreased enzymatic activity of these proteins (Figure 5) [70]. SIRT3 deacetylates SOD2 at the K68 site and increases its ROS-eliminating activity, thus repressing DA neuronal degeneration in PD [68]. Lysine acetylation changes are detectable in the mitochondria in A53T- $\alpha$-syn/PINK ${ }^{-1-}$ mice compared with wild-type controls, and SIRT3 levels are significantly decreased [125]. Furthermore, decreased expression or activity of SIRT3 contributing to increased acetylation of SOD2 is associated with genetic factors, including $\alpha$-syn and LRRK2 G2019S [63,71]. Interestingly, SIRT3 binds directly to the PD genetic factors PINK1 and Parkin and promotes their deacetylation and thus angiogenesis, and SIRT3 inhibition leads to hyperacetylation of PINK1/Parkin and impairment of mitophagy under stress [126]. However, whether the hyperacetylation of PINK1/Parkin participates directly in PD pathogenesis remains unclear. It has also been suggested that SIRT5 protects against motor deficits and DA neuron degeneration in MPTP-treated mice [127]. However, whether SIRT5 exerts a DA neuron protective function depends on its deacetylase activity, and the mechanism, is not yet clear.

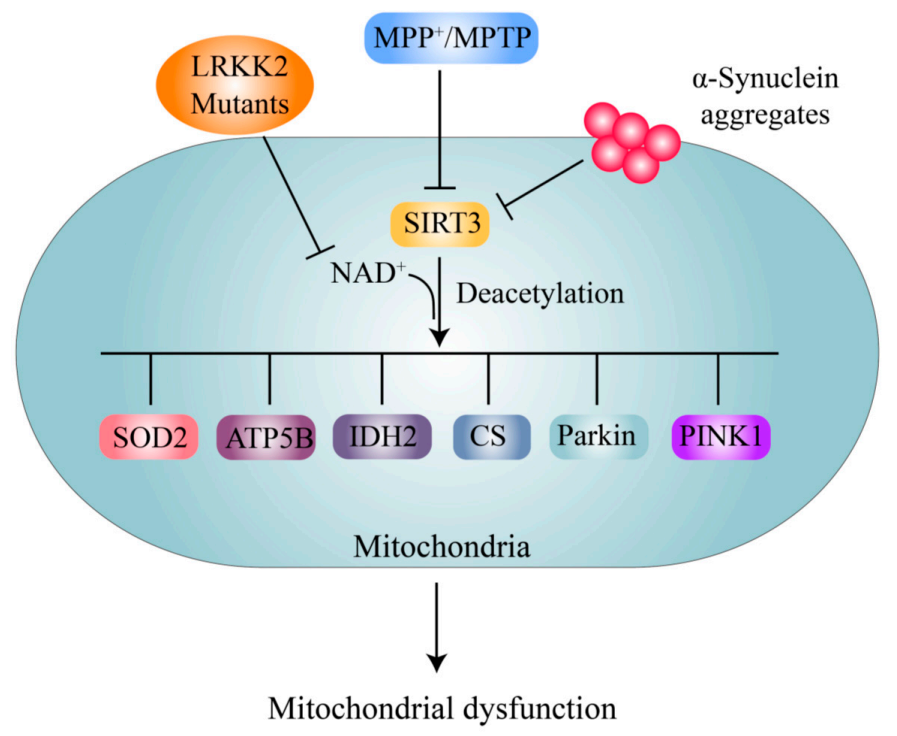

Figure 5. Acetylation of mitochondrial proteins by PD-related neurotoxins or genetic factors. $\alpha$-syn and MPTP/MPP ${ }^{+}$reduce SIRT3 expression, while LRKK2 G2109S inhibits SIRT3 activity by decreasing $\mathrm{NAD}^{+}$levels to prevent deacetylation of mitochondrial substrates, including SOD2, ATP5B, GS, and IDH2, thereby reducing their activity decline and leading to mitochondrial dysfunction.

SIRT3 plays essential roles in regulating mitochondrial functions, such as ATP generation, energy metabolism, antioxidant stress, survival, and proliferation, by deacetylating various substrates, such as long-chain acyl-CoA dehydrogenase (LCAD), ATP synthases, NADH dehydrogenase (NDUFA9), the mitochondrial protease Lon peptidase 1 (LONP1), and glycogen synthase kinase 3 beta (GSK3 $\beta$ ) [128]. Although these proteins have been implicated to play roles in PD, whether acetylation of these proteins is directly involved in PD pathogenesis still lacks relevant research. In addition, whether mitochondrial KATs, ACAT1, and GCN5L1 participate in the acetylation modification of these proteins and their roles in PD pathogenesis needs further investigation.

Although further research on SIRT3 and its substrates in the context of PD needs to be performed, activation of SIRT3 has been shown to be a very promising treatment strategy for PD. Overexpression of SIRT3 or enhancement of SIRT3 activity by NAD ${ }^{+}$precursors has been found to protect DA neurons in various PD models $[68,69,129,130]$. Recently, human clinical trials have indicated that supplementation with the $\mathrm{NAD}^{+}$precursor nicotinamide riboside (NR) is well tolerated, elevates NAD ${ }^{+}$levels in healthy adults, and reduces the levels of circulating inflammatory cytokines in patients [131,132]. 
Another $\mathrm{NAD}^{+}$precursor, nicotinamide mononucleotide $(\mathrm{NMN})$, also increases $\mathrm{NAD}^{+}$levels in mitochondria and protects mitochondria [133]. These findings suggest that $\mathrm{NAD}^{+}$precursors are potential clinical drugs for PD treatment.

\section{Conclusions and Perspectives}

Abnormal and imbalanced acetylation of histones as well as nonhistone proteins is tightly associated with many human diseases, including PD; therefore, KATs and KDACs, which directly participate in acetylation or deacetylation modification, are attractive therapeutic targets in PD treatment. Activators of SIRT1 and SIRT3 and inhibitors of SIRT2 are considered to be the most promising representative agents for the treatment of PD. Although the effects of nonspecific HDAC inhibitors are still controversial in different PD models or even in PD models of the same type, it should be noted that certain KAT inhibitors and specific HDAC inhibitors may be effective for several PD models.

Altered acetylation of histones, especially $\mathrm{H} 3$ and $\mathrm{H} 4$, has been widely studied in the context of PD. Although increased levels of histone acetylation are found in the brains of PD patients [46], histones can be either hypoacetylated or hyperacetylated in different PD models (Figure 2). Most PD-related neurotoxins, such as MPTP/MPP ${ }^{+}$, rotenone, paraquat, and dieldrin, can induce $\mathrm{H} 3$ or H4 hyperacetylation. However, genetic factors such as $\alpha$-syn and LRRK2, as well as the neurotoxin $\mathrm{Mn}$, can lead to hypoacetylation of histones. It is not yet clear whether altered histone acetylation is a causative factor of DA neurodegeneration or initiates a compensatory response to reduce DA neurodegeneration. Nevertheless, numerous studies have suggested that HAT inhibitors, HDAC inhibitors, or SIRT1 activators targeting histone acetylation balance have potential therapeutic value for various PD models. However, more selective inhibitors or activators targeting different PD models need to be selected.

Alterations in the acetylation levels of nonhistone proteins, mainly $\alpha$-tubulin at K40, contribute to the pathogenesis of PD caused by genetic factors such as $\alpha$-syn, LRRK2, Parkin, and ATP13A2 $[27,28,53,54,65]$. These alterations mainly involve changes in the activity or protein levels of SIRT2 and HDAC6, two cytoplasmic KDACs (Figure 3A). Interestingly, the acetylation of $\alpha$-syn itself can inhibit its neurotoxicity, and deacetylation by SIRT2 enhances its neurotoxicity [64]. Inhibition of SIRT2 activity is the most promising therapeutic strategy for the treatment of $\alpha$-syn-mediated neurodegeneration. However, targeting HDAC6 for PD treatment is still controversial [116]. PD-related neurotoxins cause changes in the acetylation levels of a variety of nonhistone proteins, involving alterations in signaling pathways such as autophagy, apoptosis, neuroinflammation, oxidative stress, and mitochondrial biogenesis pathways, mainly by inhibiting SIRT1 expression or activity (Figure 4). Interestingly, it can be concluded that SIRT1 activation exerts a general alleviating effect on DA neurodegeneration by targeting not only nonhistone acetylation balance but also histone acetylation balance (Figures 2 and 4). The changes in the acetylation levels of mitochondrial proteins in PD models are mainly mediated by decreased activity or protein levels of SIRT3 (Figure 5), and activation of SIRT3 is the most attractive and valuable therapeutic strategy for PD treatment.

Thus far, research on the mechanisms of changes in the acetylation levels of proteins, especially histones, that occur in PD has been very limited. More systematic and in-depth studies are needed to explore the specific KATs or KDACs related to PD pathology and their underlying mechanisms. There is also a need to clarify why changes in protein acetylation levels and related KATs or KDACs in different PD models are different or even opposite. More importantly, for preclinical research and clinical trials on PD, more specific and less toxic inhibitors or activators for KATs and KDACs must be developed.

Author Contributions: Conceptualization, H.R. and G.W.; methodology, H.R., R.W., H.S. and G.W.; software, H.R. and R.W.; validation, H.S.; investigation, H.R. and H.S.; resources, H.R. and G.W.; writing-original draft preparation H.R.; writing-review and editing, H.R. and G.W.; supervision, G.W.; funding acquisition, H.R. and G.W. All authors have read and agreed to the published version of the manuscript. 
Funding: This research was funded by the National Natural Science Foundation of China $(31970966,31871023)$, the National Key Scientific Research and Development Program of China (2016YFC1306000), Suzhou Clinical Research Center of Neurological Disease (Szzx201503), and the Priority Academic Program Development of Jiangsu Higher Education Institutions.

Conflicts of Interest: The authors declare no conflict of interest.

\section{Abbreviations}

\begin{tabular}{|c|c|}
\hline 6-OHDA & 6-hydroxydopamine \\
\hline AA & anacardic acid ACAT1 \\
\hline $\mathrm{Ac}-\mathrm{CoA}$ & Acetyltransferase 1 \\
\hline$\alpha-S y n$ & $\alpha$-synuclein \\
\hline АТР5B & ATP synthase subunit $\beta$ \\
\hline ATP13A2 & ATPase 13A2 \\
\hline BMAL1 & brain and muscle arnt-like 1 \\
\hline CS & citrate synthase \\
\hline DA & dopaminergic \\
\hline Foxo3a & Forkhead box $\mathrm{O} 3$ \\
\hline GCN5L1 & GCN5-like 1 \\
\hline GLAST & glutamate aspartate transporter \\
\hline GLT-1 & glutamate transporter 1 \\
\hline GSK $3 \beta$ & glycogen synthase kinase 3 beta \\
\hline GWASs & genome-wide association studies \\
\hline $\mathrm{H} 2 \mathrm{~A}$ & Histone 2A \\
\hline $\mathrm{H} 2 \mathrm{~B}$ & Histone 2B \\
\hline H3 & Histone 3 \\
\hline $\mathrm{H} 4$ & Histone 4 \\
\hline HAT & histone acetyltransferase \\
\hline HDAC & histone deacetylases \\
\hline HIF- $1 \alpha$ & hypoxia inducible factor $1 \alpha$ \\
\hline IDH2 & isocitrate dehydrogenase 2 \\
\hline iPSC & induced pluripotent stem cells \\
\hline KDAC & lysine deacetylase \\
\hline KAT & lysine acetyltransferase \\
\hline LBs & Lewy bodies \\
\hline LC3 & light chain 3 \\
\hline LCAD & long-chain acyl-CoA dehydrogenase \\
\hline L-DOPA & Levodopa \\
\hline LEF1 & lymphoid enhancer-binding factor 1 \\
\hline LONP1 & Lon peptidase 1 \\
\hline LRKK2 & leucine-rich repeat kinase 2 \\
\hline Mn & manganese \\
\hline $\mathrm{MPP}^{+}$ & 1-methyl-4-phenylpyridinium iodide \\
\hline MPTP & phenyl-1236-tetrahydropyridine \\
\hline MT & microtubule \\
\hline NA & not available \\
\hline $\mathrm{NaB}$ & sodium butyrate \\
\hline $\mathrm{NAD}^{+}$ & nicotinamide adenine dinucleotide \\
\hline NF- $k B$ & nuclear factor Kappa-B \\
\hline NMN & nicotinamide mononucleotide \\
\hline PD & Parkinson's disease \\
\hline PGC- $1 \alpha$ & $\begin{array}{l}\text { peroxisome proliferator-activated receptor } \gamma \\
\text { coactivator- } 1 \alpha\end{array}$ \\
\hline PINK1 & PTEN-induced putative kinase 1 \\
\hline PTM & posttranslational modification \\
\hline SAHA & hydroxamic acid \\
\hline SIRT & sirtuin \\
\hline SNpc & substantia nigra pars compacta \\
\hline SOD2 & superoxide dismutase \\
\hline TCF1 & T cell-specific transcription factor 1 \\
\hline TSA & trichostatin A \\
\hline VPA & valproate \\
\hline
\end{tabular}




\section{References}

1. de Lau, L.M.; Breteler, M.M. Epidemiology of Parkinson's disease. Lancet Neurol. 2006, 5, 525-535. [CrossRef]

2. Li, T.; Le, W. Biomarkers for Parkinson's disease: How good are they? Neurosci. Bull. 2020, 36, $183-194$. [CrossRef] [PubMed]

3. Shihabuddin, L.S.; Brundin, P.; Greenamyre, J.T.; Stephenson, D.; Sardi, S.P. New frontiers in Parkinson's disease: From genetics to the clinic. J. Neurosci. 2018, 38, 9375-9382. [CrossRef] [PubMed]

4. Poewe, W.; Seppi, K.; Tanner, C.M.; Halliday, G.M.; Brundin, P.; Volkmann, J.; Schrag, A.E.; Lang, A.E. Parkinson disease. Nat. Rev. Dis. Primers 2017, 3, 17013. [CrossRef]

5. Moore, D.J.; West, A.B.; Dawson, V.L.; Dawson, T.M. Molecular pathophysiology of Parkinson's disease. Ann. Rev. Neurosci. 2005, 28, 57-87. [CrossRef]

6. Suppa, A.; Bologna, M.; Conte, A.; Berardelli, A.; Fabbrini, G. The effect of L-dopa in Parkinson's disease as revealed by neurophysiological studies of motor and sensory functions. Exp. Rev. Neurother. 2017, 17, 181-192. [CrossRef]

7. Pang, S.Y.; Ho, P.W.; Liu, H.F.; Leung, C.T.; Li, L.; Chang, E.E.S.; Ramsden, D.B.; Ho, S.L. The interplay of aging, genetics and environmental factors in the pathogenesis of Parkinson's disease. Transl. Neurodegener. 2019, 8, 23. [CrossRef]

8. Chen, R.C.; Chang, S.F.; Su, C.L.; Chen, T.H.; Yen, M.F.; Wu, H.M.; Chen, Z.Y.; Liou, H.H. Prevalence, incidence, and mortality of PD: A door-to-door survey in Ilan county, Taiwan. Neurology 2001, 57, 1679-1686. [CrossRef]

9. Xu, X.; Wang, R.; Hao, Z.; Wang, G.; Mu, C.; Ding, J.; Sun, W.; Ren, H. DJ-1 regulates tyrosine hydroxylase expression through CaMKKbeta/CaMKIV/CREB1 pathway in vitro and in vivo. J. Cell. Physiol. 2020, 235, 869-879. [CrossRef]

10. Deng, H.; Wang, P.; Jankovic, J. The genetics of Parkinson disease. Ageing Res. Rev. 2018, 42, 72-85. [CrossRef]

11. Blauwendraat, C.; Nalls, M.A.; Singleton, A.B. The genetic architecture of Parkinson's disease. Lancet Neurol. 2020, 19, 170-178. [CrossRef]

12. Del Rey, N.L.; Quiroga-Varela, A.; Garbayo, E.; Carballo-Carbajal, I.; Fernandez-Santiago, R.; Monje, M.H.G.; Trigo-Damas, I.; Blanco-Prieto, M.J.; Blesa, J. Advances in Parkinson's disease: 200 years later. Front. Neuroanat. 2018, 12, 113. [CrossRef] [PubMed]

13. Kouli, A.; Torsney, K.M.; Kuan, W.L. Parkinson's disease: Etiology, neuropathology, and pathogenesis. In Parkinson's Disease: Pathogenesis and Clinical Aspects; Stoker, T.B., Greenland, J.C., Eds.; Codon Publications: Brisbane, Australia, 2018.

14. Sironi, L.; Restelli, L.M.; Tolnay, M.; Neutzner, A.; Frank, S. Dysregulated interorganellar crosstalk of mitochondria in the pathogenesis of Parkinson's disease. Cells 2020, 9, 233. [CrossRef] [PubMed]

15. Allfrey, V.G.; Faulkner, R.; Mirsky, A.E. Acetylation and Methylation of histones and their possible role in the regulation of rna synthesis. Proc. Natl. Acad. Sci. USA 1964, 51, 786-794. [CrossRef]

16. Tessarz, P.; Kouzarides, T. Histone core modifications regulating nucleosome structure and dynamics. Nat. Rev. Mol. Cell Biol. 2014, 15, 703-708. [CrossRef]

17. Narita, T.; Weinert, B.T.; Choudhary, C. Functions and mechanisms of non-histone protein acetylation. Nat. Rev. Mol. Cell Biol. 2019, 20, 156-174. [CrossRef]

18. Sheikh, B.N.; Akhtar, A. The many lives of KATs - detectors, integrators and modulators of the cellular environment. Nat. Rev. Genet. 2019, 20,7-23. [CrossRef]

19. Hosp, F.; Lassowskat, I.; Santoro, V.; De Vleesschauwer, D.; Fliegner, D.; Redestig, H.; Mann, M.; Christian, S.; Hannah, M.A.; Finkemeier, I. Lysine acetylation in mitochondria: From inventory to function. Mitochondrion 2017, 33, 58-71. [CrossRef]

20. Li, P.; Ge, J.; Li, H. Lysine acetyltransferases and lysine deacetylases as targets for cardiovascular disease. Nat. Rev. Cardiol. 2020, 17, 96-115. [CrossRef]

21. Drazic, A.; Myklebust, L.M.; Ree, R.; Arnesen, T. The world of protein acetylation. Biochim. Biophys. Acta 2016, 1864, 1372-1401. [CrossRef]

22. Scott, I.; Webster, B.R.; Li, J.H.; Sack, M.N. Identification of a molecular component of the mitochondrial acetyltransferase programme: A novel role for GCN5L1. Biochem. J. 2012, 443, 655-661. [CrossRef] [PubMed] 
23. Fan, J.; Shan, C.; Kang, H.B.; Elf, S.; Xie, J.; Tucker, M.; Gu, T.L.; Aguiar, M.; Lonning, S.; Chen, H.; et al. Tyr phosphorylation of PDP1 toggles recruitment between ACAT1 and SIRT3 to regulate the pyruvate dehydrogenase complex. Mol. Cell 2014, 53, 534-548. [CrossRef] [PubMed]

24. Chatterjee, A.; Seyfferth, J.; Lucci, J.; Gilsbach, R.; Preissl, S.; Bottinger, L.; Martensson, C.U.; Panhale, A.; Stehle, T.; Kretz, O.; et al. MOF acetyl transferase regulates transcription and respiration in mitochondria. Cell 2016, 167, 722-738. [CrossRef] [PubMed]

25. Guo, Z.; Zhang, Z.; Wang, Q.; Zhang, J.; Wang, L.; Zhang, Q.; Li, H.; Wu, S. Manganese chloride induces histone acetylation changes in neuronal cells: Its role in manganese-induced damage. Neurotoxicology 2018, 65, 255-263. [CrossRef] [PubMed]

26. Fan, F.; Li, S.; Wen, Z.; Ye, Q.; Chen, X.; Ye, Q. Regulation of PGC-1alpha mediated by acetylation and phosphorylation in MPP+ induced cell model of Parkinson's disease. Aging 2020, 12, 9461-9474. [CrossRef]

27. Godena, V.K.; Brookes-Hocking, N.; Moller, A.; Shaw, G.; Oswald, M.; Sancho, R.M.; Miller, C.C.; Whitworth, A.J.; De Vos, K.J. Increasing microtubule acetylation rescues axonal transport and locomotor deficits caused by LRRK2 Roc-COR domain mutations. Nat. Commun. 2014, 5, 5245. [CrossRef]

28. Law, B.M.; Spain, V.A.; Leinster, V.H.; Chia, R.; Beilina, A.; Cho, H.J.; Taymans, J.M.; Urban, M.K.; Sancho, R.M.; Blanca Ramirez, M.; et al. A direct interaction between leucine-rich repeat kinase 2 and specific beta-tubulin isoforms regulates tubulin acetylation. J. Biol. Chem. 2014, 289, 895-908. [CrossRef]

29. Kanthasamy, A.; Jin, H.; Anantharam, V.; Sondarva, G.; Rangasamy, V.; Rana, A.; Kanthasamy, A. Emerging neurotoxic mechanisms in environmental factors-induced neurodegeneration. Neurotoxicology 2012, 33, 833-837. [CrossRef]

30. Jin, H.; Kanthasamy, A.; Ghosh, A.; Yang, Y.; Anantharam, V.; Kanthasamy, A.G. alpha-Synuclein negatively regulates protein kinase Cdelta expression to suppress apoptosis in dopaminergic neurons by reducing p300 histone acetyltransferase activity. J. Neurosci. 2011, 31, 2035-2051. [CrossRef]

31. Paiva, I.; Pinho, R.; Pavlou, M.A.; Hennion, M.; Wales, P.; Schutz, A.L.; Rajput, A.; Szego, E.M.; Kerimoglu, C.; Gerhardt, E.; et al. Sodium butyrate rescues dopaminergic cells from alpha-synuclein-induced transcriptional deregulation and DNA damage. Hum. Mol. Genet. 2017, 26, 2231-2246. [CrossRef]

32. Kleff, S.; Andrulis, E.D.; Anderson, C.W.; Sternglanz, R. Identification of a gene encoding a yeast histone H4 acetyltransferase. J. Biol. Chem. 1995, 270, 24674-24677. [CrossRef]

33. Yang, X.J.; Seto, E. Lysine acetylation: Codified crosstalk with other posttranslational modifications. Mol. Cell 2008, 31, 449-461. [CrossRef] [PubMed]

34. Xing, S.; Li, F.; Zeng, Z.; Zhao, Y.; Yu, S.; Shan, Q.; Li, Y.; Phillips, F.C.; Maina, P.K.; Qi, H.H.; et al. Tcf1 and Lef1 transcription factors establish CD8(+) T cell identity through intrinsic HDAC activity. Nat. Immunol. 2016, 17, 695-703. [CrossRef] [PubMed]

35. Herr, D.J.; Baarine, M.; Aune, S.E.; Li, X.; Ball, L.E.; Lemasters, J.J.; Beeson, C.C.; Chou, J.C.; Menick, D.R. HDAC1 localizes to the mitochondria of cardiac myocytes and contributes to early cardiac reperfusion injury. J. Mol. Cell. Cardiol. 2018, 114, 309-319. [CrossRef] [PubMed]

36. Bakin, R.E.; Jung, M.O. Cytoplasmic sequestration of HDAC7 from mitochondrial and nuclear compartments upon initiation of apoptosis. J. Biol. Chem. 2004, 279, 51218-51225. [CrossRef] [PubMed]

37. Kumar, S.; Lombard, D.B. Functions of the sirtuin deacylase SIRT5 in normal physiology and pathobiology. Crit. Rev. Biochem. Mol. Biol. 2018, 53, 311-334. [CrossRef] [PubMed]

38. Anderson, K.A.; Huynh, F.K.; Fisher-Wellman, K.; Stuart, J.D.; Peterson, B.S.; Douros, J.D.; Wagner, G.R.; Thompson, J.W.; Madsen, A.S.; Green, M.F.; et al. SIRT4 Is a lysine deacylase that controls leucine metabolism and insulin secretion. Cell Metab. 2017, 25, 838-855. [CrossRef] [PubMed]

39. Jiang, H.; Khan, S.; Wang, Y.; Charron, G.; He, B.; Sebastian, C.; Du, J.; Kim, R.; Ge, E.; Mostoslavsky, R.; et al. SIRT6 regulates TNF-alpha secretion through hydrolysis of long-chain fatty acyl lysine. Nature 2013, 496, 110-113. [CrossRef] [PubMed]

40. Sabari, B.R.; Tang, Z.; Huang, H.; Yong-Gonzalez, V.; Molina, H.; Kong, H.E.; Dai, L.; Shimada, M.; Cross, J.R.; Zhao, Y.; et al. Intracellular crotonyl-CoA stimulates transcription through p300-catalyzed histone crotonylation. Mol. Cell 2015, 58, 203-215. [CrossRef]

41. Wang, Y.; Jin, J.; Chung, M.W.H.; Feng, L.; Sun, H.; Hao, Q. Identification of the YEATS domain of GAS41 as a pH-dependent reader of histone succinylation. Proc. Natl. Acad. Sci. USA 2018, 115, 2365-2370. [CrossRef] 
42. Kollenstart, L.; de Groot, A.J.L.; Janssen, G.M.C.; Cheng, X.; Vreeken, K.; Martino, F.; Cote, J.; van Veelen, P.A.; van Attikum, H. Gen5 and Esa1 function as histone crotonyltransferases to regulate crotonylation-dependent transcription. J. Biol. Chem. 2019, 294, 20122-20134. [CrossRef] [PubMed]

43. Feldman, J.L.; Baeza, J.; Denu, J.M. Activation of the protein deacetylase SIRT6 by long-chain fatty acids and widespread deacylation by mammalian sirtuins. J. Biol. Chem. 2013, 288, 31350-31356. [CrossRef] [PubMed]

44. Wei, W.; Liu, X.; Chen, J.; Gao, S.; Lu, L.; Zhang, H.; Ding, G.; Wang, Z.; Chen, Z.; Shi, T.; et al. Class I histone deacetylases are major histone decrotonylases: Evidence for critical and broad function of histone crotonylation in transcription. Cell Res. 2017, 27, 898-915. [CrossRef] [PubMed]

45. Kelly, R.D.W.; Chandru, A.; Watson, P.J.; Song, Y.; Blades, M.; Robertson, N.S.; Jamieson, A.G.; Schwabe, J.W.R.; Cowley, S.M. Histone deacetylase (HDAC) 1 and 2 complexes regulate both histone acetylation and crotonylation in vivo. Sci. Rep. 2018, 8, 14690. [CrossRef] [PubMed]

46. Park, G.; Tan, J.; Garcia, G.; Kang, Y.; Salvesen, G.; Zhang, Z. Regulation of histone acetylation by autophagy in Parkinson disease. J. Biol. Chem. 2016, 291, 3531-3540. [CrossRef] [PubMed]

47. Choong, C.J.; Sasaki, T.; Hayakawa, H.; Yasuda, T.; Baba, K.; Hirata, Y.; Uesato, S.; Mochizuki, H. A novel histone deacetylase 1 and 2 isoform-specific inhibitor alleviates experimental Parkinson's disease. Neurobiol. Aging 2016, 37, 103-116. [CrossRef]

48. Yakhine-Diop, S.M.S.; Niso-Santano, M.; Rodriguez-Arribas, M.; Gomez-Sanchez, R.; Martinez-Chacon, G.; Uribe-Carretero, E.; Navarro-Garcia, J.A.; Ruiz-Hurtado, G.; Aiastui, A.; Cooper, J.M.; et al. Impaired mitophagy and protein acetylation levels in fibroblasts from Parkinson's disease patients. Mol. Neurobiol. 2019, 56, 2466-2481. [CrossRef]

49. Han, K.A.; Shin, W.H.; Jung, S.; Seol, W.; Seo, H.; Ko, C.; Chung, K.C. Leucine-rich repeat kinase 2 exacerbates neuronal cytotoxicity through phosphorylation of histone deacetylase 3 and histone deacetylation. Hum. Mol. Genet. 2017, 26, 1-18. [CrossRef]

50. Choi, H.K.; Choi, Y.; Kang, H.; Lim, E.J.; Park, S.Y.; Lee, H.S.; Park, J.M.; Moon, J.; Kim, Y.J.; Choi, I.; et al. PINK1 positively regulates HDAC3 to suppress dopaminergic neuronal cell death. Hum. Mol. Genet. 2015, 24, 1127-1141. [CrossRef]

51. Song, C.; Kanthasamy, A.; Anantharam, V.; Sun, F.; Kanthasamy, A.G. Environmental neurotoxic pesticide increases histone acetylation to promote apoptosis in dopaminergic neuronal cells: Relevance to epigenetic mechanisms of neurodegeneration. Mol. Pharmacol. 2010, 77, 621-632. [CrossRef]

52. Song, C.; Kanthasamy, A.; Jin, H.; Anantharam, V.; Kanthasamy, A.G. Paraquat induces epigenetic changes by promoting histone acetylation in cell culture models of dopaminergic degeneration. Neurotoxicology 2011, 32, 586-595. [CrossRef] [PubMed]

53. Cartelli, D.; Amadeo, A.; Calogero, A.M.; Casagrande, F.V.M.; De Gregorio, C.; Gioria, M.; Kuzumaki, N.; Costa, I.; Sassone, J.; Ciammola, A.; et al. Parkin absence accelerates microtubule aging in dopaminergic neurons. Neurobiol. Aging 2018, 61, 66-74. [CrossRef] [PubMed]

54. Wang, R.; Tan, J.; Chen, T.; Han, H.; Tian, R.; Tan, Y.; Wu, Y.; Cui, J.; Chen, F.; Li, J.; et al. ATP13A2 facilitates HDAC6 recruitment to lysosome to promote autophagosome-lysosome fusion. J. Cell Biol. 2019, 218, 267-284. [CrossRef] [PubMed]

55. Jian, W.; Wei, X.; Chen, L.; Wang, Z.; Sun, Y.; Zhu, S.; Lou, H.; Yan, S.; Li, X.; Zhou, J.; et al. Inhibition of HDAC6 increases acetylation of peroxiredoxin1/2 and ameliorates 6-OHDA induced dopaminergic injury. Neurosci. Lett. 2017, 658, 114-120. [CrossRef]

56. Singh, P.; Hanson, P.S.; Morris, C.M. SIRT1 ameliorates oxidative stress induced neural cell death and is down-regulated in Parkinson's disease. BMC Neurosci. 2017, 18, 46. [CrossRef]

57. Guo, Y.J.; Dong, S.Y.; Cui, X.X.; Feng, Y.; Liu, T.; Yin, M.; Kuo, S.H.; Tan, E.K.; Zhao, W.J.; Wu, Y.C. Resveratrol alleviates MPTP-induced motor impairments and pathological changes by autophagic degradation of alpha-synuclein via SIRT1-deacetylated LC3. Mol. Nutr. Food Res. 2016, 60, 2161-2175. [CrossRef]

58. Shinozaki, S.; Chang, K.; Sakai, M.; Shimizu, N.; Yamada, M.; Tanaka, T.; Nakazawa, H.; Ichinose, F.; Yamada, Y.; Ishigami, A.; et al. Inflammatory stimuli induce inhibitory S-nitrosylation of the deacetylase SIRT1 to increase acetylation and activation of p53 and p65. Sci. Sign. 2014, 7, ra106. [CrossRef]

59. Dong, S.Y.; Guo, Y.J.; Feng, Y.; Cui, X.X.; Kuo, S.H.; Liu, T.; Wu, Y.C. The epigenetic regulation of HIF-1alpha by SIRT1 in MPP (+) treated SH-SY5Y cells. Biochem. Biophys. Res. Commun. 2016, 470, 453-459. [CrossRef] 
60. Feng, Y.; Liu, T.; Dong, S.Y.; Guo, Y.J.; Jankovic, J.; Xu, H.; Wu, Y.C. Rotenone affects p53 transcriptional activity and apoptosis via targeting SIRT1 and H3K9 acetylation in SH-SY5Y cells. J. Neurochem. 2015, 134, 668-676. [CrossRef]

61. Tao, H.; Liu, Y.; Hou, Y. miRNA3845p regulates the progression of Parkinson's disease by targeting SIRT1 in mice and SHSY5Y cell. Int. J. Mol. Med. 2020, 45, 441-450.

62. Wang, Y.; Lv, D.; Liu, W.; Li, S.; Chen, J.; Shen, Y.; Wang, F.; Hu, L.F.; Liu, C.F. Disruption of the circadian clock alters antioxidative defense via the SIRT1-BMAL1 pathway in 6-OHDA-induced models of Parkinson's disease. Oxid. Med. Cell. Longev. 2018, 2018, 4854732. [CrossRef] [PubMed]

63. Schwab, A.J.; Sison, S.L.; Meade, M.R.; Broniowska, K.A.; Corbett, J.A.; Ebert, A.D. Decreased sirtuin deacetylase activity in LRRK2 G2019S iPSC-derived dopaminergic neurons. Stem Cell Rep. 2017, 9, 1839-1852. [CrossRef]

64. de Oliveira, R.M.; Vicente Miranda, H.; Francelle, L.; Pinho, R.; Szego, E.M.; Martinho, R.; Munari, F.; Lazaro, D.F.; Moniot, S.; Guerreiro, P.; et al. The mechanism of sirtuin 2-mediated exacerbation of alpha-synuclein toxicity in models of Parkinson disease. PLoS Biol. 2017, 15, e2000374. [CrossRef] [PubMed]

65. Esteves, A.R.; Palma, A.M.; Gomes, R.; Santos, D.; Silva, D.F.; Cardoso, S.M. Acetylation as a major determinant to microtubule-dependent autophagy: Relevance to Alzheimer's and Parkinson disease pathology. Biochim. Biophys. Acta Mol. Basis Dis. 2019, 1865, 2008-2023. [CrossRef] [PubMed]

66. Liu, L.; Arun, A.; Ellis, L.; Peritore, C.; Donmez, G. SIRT2 enhances 1-methyl-4-phenyl-1,2,3,6tetrahydropyridine (MPTP)-induced nigrostriatal damage via apoptotic pathway. Front. Aging Neurosci. 2014, 6, 184. [CrossRef]

67. Patel, V.P.; Chu, C.T. Decreased SIRT2 activity leads to altered microtubule dynamics in oxidatively-stressed neuronal cells: Implications for Parkinson's disease. Exp. Neurol. 2014, 257, 170-181. [CrossRef] [PubMed]

68. Shi, H.; Deng, H.X.; Gius, D.; Schumacker, P.T.; Surmeier, D.J.; Ma, Y.C. Sirt3 protects dopaminergic neurons from mitochondrial oxidative stress. Hum. Mol. Genet. 2017, 26, 1915-1926. [CrossRef]

69. Zhang, X.; Ren, X.; Zhang, Q.; Li, Z.; Ma, S.; Bao, J.; Li, Z.; Bai, X.; Zheng, L.; Zhang, Z.; et al. PGC-1alpha/ERRalpha-Sirt3 pathway regulates DAergic neuronal death by directly deacetylating SOD2 and ATP Synthase beta. Antioxid. Redox Sign. 2016, 24, 312-328. [CrossRef]

70. Cui, X.X.; Li, X.; Dong, S.Y.; Guo, Y.J.; Liu, T.; Wu, Y.C. SIRT3 deacetylated and increased citrate synthase activity in PD model. Biochem. Biophys. Res. Commun. 2017, 484, 767-773. [CrossRef]

71. Park, J.H.; Burgess, J.D.; Faroqi, A.H.; DeMeo, N.N.; Fiesel, F.C.; Springer, W.; Delenclos, M.; McLean, P.J. Alpha-synuclein-induced mitochondrial dysfunction is mediated via a sirtuin 3-dependent pathway. Mol. Neurodegener. 2020, 15, 5. [CrossRef]

72. He, H.; Hu, Z.; Xiao, H.; Zhou, F.; Yang, B. The tale of histone modifications and its role in multiple sclerosis. Hum. Genom. 2018, 12, 31. [CrossRef] [PubMed]

73. Yu, G.; Wu, Q.; Gao, Y.; Chen, M.; Yang, M. The epigenetics of aging in invertebrates. Int. J. Mol. Sci. 2019, 20, 4535. [CrossRef] [PubMed]

74. Bannister, A.J.; Kouzarides, T. Regulation of chromatin by histone modifications. Cell Res. 2011, 21, $381-395$. [CrossRef]

75. Filippakopoulos, P.; Knapp, S. Targeting bromodomains: Epigenetic readers of lysine acetylation. Nat. Rev. Drug Discov. 2014, 13, 337-356. [CrossRef]

76. Gebremedhin, K.G.; Rademacher, D.J. Histone H3 acetylation in the postmortem Parkinson's disease primary motor cortex. Neurosci. Lett. 2016, 627, 121-125. [CrossRef] [PubMed]

77. Harrison, I.F.; Smith, A.D.; Dexter, D.T. Pathological histone acetylation in Parkinson's disease: Neuroprotection and inhibition of microglial activation through SIRT 2 inhibition. Neurosci. Lett. 2018, 666, 48-57. [CrossRef] [PubMed]

78. Yakhine-Diop, S.M.S.; Rodriguez-Arribas, M.; Martinez-Chacon, G.; Uribe-Carretero, E.; Gomez-Sanchez, R.; Aiastui, A.; Lopez de Munain, A.; Bravo-San Pedro, J.M.; Niso-Santano, M.; Gonzalez-Polo, R.A.; et al. Acetylome in human fibroblasts from Parkinson's disease patients. Front. Cell. Neurosci. 2018, $12,97$. [CrossRef]

79. Yakhine-Diop, S.M.S.; Martinez-Chacon, G.; Uribe-Carretero, E.; Niso-Santano, M.; Gonzalez-Polo, R.A.; Fuentes, J.M. The paradigm of protein acetylation in Parkinson's disease. Neural Regen. Res. 2019, 14, 975-976. 
80. Nicholas, A.P.; Lubin, F.D.; Hallett, P.J.; Vattem, P.; Ravenscroft, P.; Bezard, E.; Zhou, S.; Fox, S.H.; Brotchie, J.M.; Sweatt, J.D.; et al. Striatal histone modifications in models of levodopa-induced dyskinesia. J. Neurochem. 2008, 106, 486-494. [CrossRef]

81. Ryu, Y.K.; Park, H.Y.; Go, J.; Kim, Y.H.; Hwang, J.H.; Choi, D.H.; Noh, J.R.; Rhee, M.; Han, P.L.; Lee, C.H.; et al. Effects of histone acetyltransferase inhibitors on L-DOPA-induced dyskinesia in a murine model of Parkinson's disease. J. Neural Transm. 2018, 125, 1319-1331. [CrossRef]

82. Johnson, J., Jr.; Pajarillo, E.; Karki, P.; Kim, J.; Son, D.S.; Aschner, M.; Lee, E. Valproic acid attenuates manganese-induced reduction in expression of GLT-1 and GLAST with concomitant changes in murine dopaminergic neurotoxicity. Neurotoxicology 2018, 67, 112-120. [CrossRef] [PubMed]

83. Deb, S.; Phukan, B.C.; Mazumder, M.K.; Dutta, A.; Paul, R.; Bhattacharya, P.; Sandhir, R.; Borah, A. Garcinol, a multifaceted sword for the treatment of Parkinson's disease. Neurochem. Int. 2019, 128, 50-57. [CrossRef] [PubMed]

84. Collins, H.M.; Abdelghany, M.K.; Messmer, M.; Yue, B.; Deeves, S.E.; Kindle, K.B.; Mantelingu, K.; Aslam, A.; Winkler, G.S.; Kundu, T.K.; et al. Differential effects of garcinol and curcumin on histone and p53 modifications in tumour cells. BMC Cancer 2013, 13, 37. [CrossRef] [PubMed]

85. Tomeh, M.A.; Hadianamrei, R.; Zhao, X. A review of curcumin and its derivatives as anticancer agents. Int. J. Mol. Sci. 2019, 20, 1033. [CrossRef] [PubMed]

86. Feng, Y.; Jankovic, J.; Wu, Y.C. Epigenetic mechanisms in Parkinson's disease. J. Neurol. Sci. 2015, 349, 3-9. [CrossRef] [PubMed]

87. Polymeropoulos, M.H.; Lavedan, C.; Leroy, E.; Ide, S.E.; Dehejia, A.; Dutra, A.; Pike, B.; Root, H.; Rubenstein, J.; Boyer, R.; et al. Mutation in the alpha-synuclein gene identified in families with Parkinson's disease. Science 1997, 276, 2045-2047. [CrossRef]

88. Wang, R.; Sun, H.; Ren, H.; Wang, G. Alpha-Synuclein aggregation and transmission in Parkinson's disease: A link to mitochondria and lysosome. Sci. China Life Sci. 2020. [CrossRef]

89. Goers, J.; Manning-Bog, A.B.; McCormack, A.L.; Millett, I.S.; Doniach, S.; Di Monte, D.A.; Uversky, V.N.; Fink, A.L. Nuclear localization of alpha-synuclein and its interaction with histones. Biochemistry 2003, 42, 8465-8471. [CrossRef]

90. Kontopoulos, E.; Parvin, J.D.; Feany, M.B. Alpha-synuclein acts in the nucleus to inhibit histone acetylation and promote neurotoxicity. Hum. Mol. Genet. 2006, 15, 3012-3023. [CrossRef] [PubMed]

91. Monti, B.; Gatta, V.; Piretti, F.; Raffaelli, S.S.; Virgili, M.; Contestabile, A. Valproic acid is neuroprotective in the rotenone rat model of Parkinson's disease: Involvement of alpha-synuclein. Neurotox. Res. 2010, 17, 130-141. [CrossRef]

92. Ammal Kaidery, N.; Tarannum, S.; Thomas, B. Epigenetic landscape of Parkinson's disease: Emerging role in disease mechanisms and therapeutic modalities. Neurotherapeutics 2013, 10, 698-708. [CrossRef] [PubMed]

93. Siddiqui, A.; Chinta, S.J.; Mallajosyula, J.K.; Rajagopolan, S.; Hanson, I.; Rane, A.; Melov, S.; Andersen, J.K. Selective binding of nuclear alpha-synuclein to the PGC1alpha promoter under conditions of oxidative stress may contribute to losses in mitochondrial function: Implications for Parkinson's disease. Free Radic. Biol. Med. 2012, 53, 993-1003. [CrossRef] [PubMed]

94. Kim, T.; Song, S.; Park, Y.; Kang, S.; Seo, H. HDAC inhibition by valproic acid induces neuroprotection and improvement of PD-like behaviors in LRRK2 R1441G transgenic mice. Exp. Neurobiol. 2019, 28, 504-515. [CrossRef] [PubMed]

95. Goldman, S.M. Environmental toxins and Parkinson's disease. Ann. Rev. Pharmacol. Toxicol. 2014, 54, 141-164. [CrossRef]

96. Harischandra, D.S.; Rokad, D.; Neal, M.L.; Ghaisas, S.; Manne, S.; Sarkar, S.; Panicker, N.; Zenitsky, G.; Jin, H.; Lewis, M.; et al. Manganese promotes the aggregation and prion-like cell-to-cell exosomal transmission of alpha-synuclein. Sci. Sign. 2019, 12, 4543. [CrossRef]

97. Voutsinas, G.E.; Stavrou, E.F.; Karousos, G.; Dasoula, A.; Papachatzopoulou, A.; Syrrou, M.; Verkerk, A.J.; van der Spek, P.; Patrinos, G.P.; Stoger, R.; et al. Allelic imbalance of expression and epigenetic regulation within the alpha-synuclein wild-type and p.Ala53Thr alleles in Parkinson disease. Hum. Mutat. 2010, 31, 685-691. [CrossRef]

98. Vermunt, M.W.; Reinink, P.; Korving, J.; de Bruijn, E.; Creyghton, P.M.; Basak, O.; Geeven, G.; Toonen, P.W.; Lansu, N.; Meunier, C.; et al. Large-scale identification of coregulated enhancer networks in the adult human brain. Cell Rep. 2014, 9, 767-779. [CrossRef] 
99. Liu, P.; Sun, L.; Zhao, X.L.; Zhang, P.; Zhao, X.M.; Zhang, J. PAR2-mediated epigenetic upregulation of alpha-synuclein contributes to the pathogenesis of Parkinsons disease. Brain Res. 2014, 1565, 82-89. [CrossRef]

100. Fauvet, B.; Fares, M.B.; Samuel, F.; Dikiy, I.; Tandon, A.; Eliezer, D.; Lashuel, H.A. Characterization of semisynthetic and naturally Nalpha-acetylated alpha-synuclein in vitro and in intact cells: Implications for aggregation and cellular properties of alpha-synuclein. J. Biol. Chem. 2012, 287, 28243-28262. [CrossRef]

101. Gruschus, J.M.; Yap, T.L.; Pistolesi, S.; Maltsev, A.S.; Lee, J.C. NMR structure of calmodulin complexed to an $\mathrm{N}$-terminally acetylated alpha-synuclein peptide. Biochemistry 2013, 52, 3436-3445. [CrossRef]

102. Bu, B.; Tong, X.; Li, D.; Hu, Y.; He, W.; Zhao, C.; Hu, R.; Li, X.; Shao, Y.; Liu, C.; et al. N-terminal acetylation preserves alpha-synuclein from oligomerization by blocking intermolecular hydrogen bonds. ACS Chem. Neurosci. 2017, 8, 2145-2151. [CrossRef] [PubMed]

103. Kang, L.; Moriarty, G.M.; Woods, L.A.; Ashcroft, A.E.; Radford, S.E.; Baum, J. N-terminal acetylation of alpha-synuclein induces increased transient helical propensity and decreased aggregation rates in the intrinsically disordered monomer. Protein Sci. 2012, 21, 911-917. [CrossRef] [PubMed]

104. Outeiro, T.F.; Kontopoulos, E.; Altmann, S.M.; Kufareva, I.; Strathearn, K.E.; Amore, A.M.; Volk, C.B.; Maxwell, M.M.; Rochet, J.C.; McLean, P.J.; et al. Sirtuin 2 inhibitors rescue alpha-synuclein-mediated toxicity in models of Parkinson's disease. Science 2007, 317, 516-519. [CrossRef] [PubMed]

105. Kazantsev, A.G.; Kolchinsky, A.M. Central role of alpha-synuclein oligomers in neurodegeneration in Parkinson disease. Arch. Neurol. 2008, 65, 1577-1581. [CrossRef] [PubMed]

106. Francelle, L.; Outeiro, T.F.; Rappold, G.A. Inhibition of HDAC6 activity protects dopaminergic neurons from alpha-synuclein toxicity. Sci. Rep. 2020, 10, 6064. [CrossRef] [PubMed]

107. Du, G.; Liu, X.; Chen, X.; Song, M.; Yan, Y.; Jiao, R.; Wang, C.C. Drosophila histone deacetylase 6 protects dopaminergic neurons against \{alpha\}-synuclein toxicity by promoting inclusion formation. Mol. Biol. Cell 2010, 21, 2128-2137. [CrossRef]

108. Du, Y.; Wang, F.; Zou, J.; Le, W.; Dong, Q.; Wang, Z.; Shen, F.; Yu, L.; Li, Y. Histone deacetylase 6 regulates cytotoxic alpha-synuclein accumulation through induction of the heat shock response. Neurobiol. Aging 2014, 35, 2316-2328. [CrossRef]

109. Su, M.; Shi, J.J.; Yang, Y.P.; Li, J.; Zhang, Y.L.; Chen, J.; Hu, L.F.; Liu, C.F. HDAC6 regulates aggresome-autophagy degradation pathway of alpha-synuclein in response to MPP+-induced stress. J. Neurochem. 2011, 117, 112-120. [CrossRef]

110. Jiang, Q.; Ren, Y.; Feng, J. Direct binding with histone deacetylase 6 mediates the reversible recruitment of parkin to the centrosome. J. Neurosci. 2008, 28, 12993-13002. [CrossRef]

111. Lee, J.Y.; Nagano, Y.; Taylor, J.P.; Lim, K.L.; Yao, T.P. Disease-causing mutations in parkin impair mitochondrial ubiquitination, aggregation, and HDAC6-dependent mitophagy. J. Cell Biol. 2010, 189, 671-679. [CrossRef]

112. Valente, E.M.; Bentivoglio, A.R.; Dixon, P.H.; Ferraris, A.; Ialongo, T.; Frontali, M.; Albanese, A.; Wood, N.W. Localization of a novel locus for autosomal recessive early-onset parkinsonism, PARK6, on human chromosome 1p35-p36. Am. J. Hum. Genet. 2001, 68, 895-900. [CrossRef] [PubMed]

113. Valente, E.M.; Abou-Sleiman, P.M.; Caputo, V.; Muqit, M.M.; Harvey, K.; Gispert, S.; Ali, Z.; Del Turco, D.; Bentivoglio, A.R.; Healy, D.G.; et al. Hereditary early-onset Parkinson's disease caused by mutations in PINK1. Science 2004, 304, 1158-1160. [CrossRef] [PubMed]

114. Hubbert, C.; Guardiola, A.; Shao, R.; Kawaguchi, Y.; Ito, A.; Nixon, A.; Yoshida, M.; Wang, X.F.; Yao, T.P. HDAC6 is a microtubule-associated deacetylase. Nature 2002, 417, 455-458. [CrossRef] [PubMed]

115. North, B.J.; Marshall, B.L.; Borra, M.T.; Denu, J.M.; Verdin, E. The human Sir2 ortholog, SIRT2, is an NAD+-dependent tubulin deacetylase. Mol. Cell 2003, 11, 437-444. [CrossRef]

116. Simoes-Pires, C.; Zwick, V.; Nurisso, A.; Schenker, E.; Carrupt, P.A.; Cuendet, M. HDAC6 as a target for neurodegenerative diseases: What makes it different from the other HDACs? Mol. Neurodegener. 2013, 8, 7. [CrossRef]

117. Corona, J.C.; Duchen, M.R. PPARgamma and PGC-1alpha as therapeutic targets in Parkinson's. Neurochem. Res. 2015, 40, 308-316. [CrossRef]

118. Lerin, C.; Rodgers, J.T.; Kalume, D.E.; Kim, S.H.; Pandey, A.; Puigserver, P. GCN5 acetyltransferase complex controls glucose metabolism through transcriptional repression of PGC-1alpha. Cell Metab. 2006, 3, 429-438. [CrossRef] 
119. Nemoto, S.; Fergusson, M.M.; Finkel, T. SIRT1 functionally interacts with the metabolic regulator and transcriptional coactivator PGC-1\{alpha\}. J. Biol. Chem. 2005, 280, 16456-16460. [CrossRef]

120. Yan, S.; Wei, X.; Jian, W.; Qin, Y.; Liu, J.; Zhu, S.; Jiang, F.; Lou, H.; Zhang, B. Pharmacological inhibition of HDAC6 attenuates NLRP3 inflammatory response and protects dopaminergic neurons in experimental models of Parkinson's disease. Front. Aging Neurosci. 2020, 12, 78. [CrossRef]

121. Hegarty, S.V.; O’Leary, E.; Solger, F.; Stanicka, J.; Sullivan, A.M.; O’Keeffe, G.W. A small molecule activator of p300/CBP histone acetyltransferase promotes survival and neurite growth in a cellular model of Parkinson's disease. Neurotox. Res. 2016, 30, 510-520. [CrossRef]

122. Hu, Q.; Wang, G. Mitochondrial dysfunction in Parkinson's disease. Transl. Neurodegener. 2016, 5, 14. [CrossRef] [PubMed]

123. Carrico, C.; Meyer, J.G.; He, W.; Gibson, B.W.; Verdin, E. The mitochondrial acylome emerges: Proteomics, regulation by sirtuins, and metabolic and disease implications. Cell Metab. 2018, 27, 497-512. [CrossRef] [PubMed]

124. Vargas-Ortiz, K.; Perez-Vazquez, V.; Macias-Cervantes, M.H. Exercise and sirtuins: A way to mitochondrial health in skeletal muscle. Int. J. Mol. Sci. 2019, 20, 2717. [CrossRef] [PubMed]

125. Auburger, G.; Gispert, S.; Jendrach, M. Mitochondrial acetylation and genetic models of Parkinson's disease. Progr. Mol. Biol. Transl. Sci. 2014, 127, 155-182.

126. Wei, T.; Huang, G.; Gao, J.; Huang, C.; Sun, M.; Wu, J.; Bu, J.; Shen, W. Sirtuin 3 deficiency accelerates hypertensive cardiac remodeling by impairing angiogenesis. J. Am. Heart Assoc. 2017, 6, e006114. [CrossRef]

127. Liu, L.; Peritore, C.; Ginsberg, J.; Shih, J.; Arun, S.; Donmez, G. Protective role of SIRT5 against motor deficit and dopaminergic degeneration in MPTP-induced mice model of Parkinson's disease. Behav. Brain Res. 2015, 281, 215-221. [CrossRef]

128. Zhou, Z.D.; Tan, E.K. Oxidized nicotinamide adenine dinucleotide-dependent mitochondrial deacetylase sirtuin-3 as a potential therapeutic target of Parkinson's disease. Ageing Res. Rev. 2020, 62, 101107. [CrossRef]

129. Schondorf, D.C.; Ivanyuk, D.; Baden, P.; Sanchez-Martinez, A.; De Cicco, S.; Yu, C.; Giunta, I.; Schwarz, L.K.; Di Napoli, G.; Panagiotakopoulou, V.; et al. The NAD+ precursor nicotinamide riboside rescues mitochondrial defects and neuronal loss in iPSC and fly models of Parkinson's disease. Cell Rep. 2018, 23, 2976-2988. [CrossRef]

130. Gleave, J.A.; Arathoon, L.R.; Trinh, D.; Lizal, K.E.; Giguere, N.; Barber, J.H.M.; Najarali, Z.; Khan, M.H.; Thiele, S.L.; Semmen, M.S.; et al. Sirtuin 3 rescues neurons through the stabilisation of mitochondrial biogenetics in the virally-expressing mutant alpha-synuclein rat model of parkinsonism. Neurobiol. Dis. 2017, 106, 133-146. [CrossRef]

131. Martens, C.R.; Denman, B.A.; Mazzo, M.R.; Armstrong, M.L.; Reisdorph, N.; McQueen, M.B.; Chonchol, M.; Seals, D.R. Chronic nicotinamide riboside supplementation is well-tolerated and elevates NAD (+) in healthy middle-aged and older adults. Nat. Commun. 2018, 9, 1286. [CrossRef]

132. Elhassan, Y.S.; Kluckova, K.; Fletcher, R.S.; Schmidt, M.S.; Garten, A.; Doig, C.L.; Cartwright, D.M.; Oakey, L.; Burley, C.V.; Jenkinson, N.; et al. Nicotinamide riboside augments the aged human skeletal muscle NAD $(+)$ metabolome and induces transcriptomic and anti-inflammatory signatures. Cell Rep. 2019, 28, 1717-1728. [CrossRef] [PubMed]

133. Poddar, S.K.; Sifat, A.E.; Haque, S.; Nahid, N.A.; Chowdhury, S.; Mehedi, I. Nicotinamide mononucleotide: Exploration of diverse therapeutic applications of a potential molecule. Biomolecules 2019, 9, 34. [CrossRef] [PubMed]

(C) 2020 by the authors. Licensee MDPI, Basel, Switzerland. This article is an open access article distributed under the terms and conditions of the Creative Commons Attribution (CC BY) license (http://creativecommons.org/licenses/by/4.0/). 